\title{
Compartimentação hidroestrutural e aptidões químicas do Sistema Aquífero Serra Geral no estado do Paraná
}

\author{
Gustavo Barbosa Athayde ${ }^{1 *}$, Camila de Vasconcelos Müller Athayde ${ }^{1}$,Ernani Francisco da Rosa Filho ${ }^{2}$
}

\begin{abstract}
Resumo A comprovada capacidade de abastecimento do Sistema Aquífero Serra Geral no estado do Paraná, associada à qualidade química das águas, demonstram a importância estratégica deste aquífero. Este trabalho caracterizou o Sistema Aquífero Serra Geral no Estado do Paraná mediante aspectos hidroestruturais e hidroquímicos regionais (aptidão in natura para consumo e irrigação). A análise das curvas potenciométricas permitiu identificar a coincidência geográfica, em escala regional, entre os divisores de água superficiais e subterrâneos. Considerando toda extensão do aquífero no estado do Paraná, o fluxo subterrâneo regional dá-se de leste para oeste, sentido às áreas de descarga situadas nas regiões oeste e noroeste, junto aos rios Paraná (principal área de descarga regional) e Paranapanema, respectivamente. A média geométrica dos valores de vazão para 337 poços tubulares é igual a 21,5 $\mathrm{m}^{3} \cdot \mathrm{h}^{-1}$. Duas Províncias Hidroestruturais foram propostas a partir do zoneamento quantitativo das vazões e capacidade específica. Poços mais produtivos localizam-se a noroeste do Lineamento Jacutinga e os menos produtivos a sudeste. Quatro 'Compartimentos Hidroestruturais' foram delimitados a partir do detalhamento das duas Províncias Hidroestruturais. Do total de 337 amostras de água analisadas, predominaram águas do tipo bicarbonatada cálcica (198 amostras); secundariamente águas bicarbonatadas sódicas (50 amostras); seguidas por águas bicarbonatadas cálcio-magnesianas (25 amostras), carbonatadas sódicas (23 amostras), bicarbonatada cálcio-sódica (19 amostras), bicarbonatadas sódio-cálcicas (13 amostras). Em menor quantidade ocorrem os seguintes tipos hidroquímicos: bicarbonatada sulfatada-sódica; bicarbonatada-carbonatada sódica; sulfatada sódica; bicarbonatada magnésio-cálcica; bicarbonatada nitrato-sódica e nitratada cálcio-sódica. O entendimento de aspectos estruturais e hidrogeológicos reduzem significativamente o risco exploratório.
\end{abstract}

Palavras-chave: Compartimentos Hidroestruturais; Sistema Aquífero Serra Geral; estado do Paraná.

\begin{abstract}
Hydrostructural compartments and chemical suitability on Serra Geral Aquifer System in the Paraná state. The ability of Serra Geral Aquifer System in the state of Paraná, to public supply and the water chemistry, demonstrate the strategic importance of this aquifer. The main objective of this study was to characterize the Serra Geral Aquifer System in the State of Paraná by hydrostructural aspects and regional hydrochemical (in natura for public supply and irrigation). The potentiometric surface identified the geographic coincidence, on a regional scale, between surface water and groundwater basins. Considering the full exposed area in the Paraná State, the regional groundwater flow is from east to west, towards the discharge areas located along the rivers Parana (principal discharge area) and Paranapanema, respectively. The geometric mean values of flow is $21.5 \mathrm{~m}^{3} \cdot \mathrm{h}^{-1}$. Two Hydrostructural Provinces were proposed considering flow and specific capacity. Most productive wells are located northwest of Jacutinga Lineament and the least productive southeast. Four 'Hydrostructural Compartments' were delimited from the two Hydrostructural Provinces. A total of 337 water samples were analyzed. The predominant water type is $\mathrm{Ca}^{+2}-\mathrm{HCO}_{3}^{-}(198$ samples $)$; secondarily $\mathrm{Na}^{+}-\mathrm{HCO}_{3}^{-}(50$ samples $)$, followed by $\mathrm{Ca}^{+2}-\mathrm{MG}^{+2}-\mathrm{HCO}_{3}^{-}$(25 samples), $\mathrm{Na}^{+}-\mathrm{CO}_{3}^{-2}$ (23 samples), $\mathrm{Ca}^{+2}-\mathrm{Na}^{+}-\mathrm{HCO}_{3}^{-}\left(19\right.$ samples), $\mathrm{Na}^{+}-\mathrm{Ca}^{+2}-$ $\mathrm{HCO}_{3}^{-}$(13 samples). Other waters types occurs: $\mathrm{Na}^{+}-\mathrm{HCO}_{3}^{-}-\mathrm{SO}_{4}^{-2}, \mathrm{Na}^{+}-\mathrm{CO}_{3}^{-2}-\mathrm{HCO}_{3}^{-}, \mathrm{Na}^{+}-\mathrm{SO}_{4}^{-2}, \mathrm{Mg}^{+2}-\mathrm{Ca}^{+2}-\mathrm{HCO}_{3}^{-}$, $\mathrm{NO}_{3}^{-}-\mathrm{Na}^{+}-\mathrm{HCO}_{3}^{-}, \mathrm{Ca}^{+2}-\mathrm{Na}^{+}-\mathrm{NO}_{3}^{-}$. Understanding the structural and hydrogeological significantly reduce exploration risk.
\end{abstract}

Keywords: Hydrostructural Compartments; Serra Geral Aquifer System; Paraná state.

INTRODUÇÃo Sistema Aquífero Serra Geral (SASG) é a denominação utilizada para referir-se ao aquífero fraturado vulcânico, representado pelas propriedades petrofísicas da Formação Serra Geral, sequência vulcânica que ocorre, dentre outros estados, no Terceiro Planalto Paranaense (Fig. 1).

A área de ocorrência do SASG no Paraná corresponde a aproximadamente $109.000 \mathrm{~km}^{2}$, as espessuras máximas atingem até $1.347 \mathrm{~m}$ (município de Cianorte - PR).

A anisotropia estrutural do SASG representa os registros atectônicos do ambiente deposicional vulcânico (derrames, fluxos piroclásticos, fluxos subaquosos, em diferentes graus e escalas de intensidade), assim como estruturas tectônicas relacionadas aos eventos deformacionais superimpostos,

${ }^{1}$ Programa de Pós-graduação em Geologia, Universidade Federal do Paraná - UFPR, Curitiba (PR), Brasil.

E-mails: gustavo_athayde@yahoo.com.br, camilavmuller@yahoo.com.br

${ }^{2}$ Departamento de Geologia da UFPR, Curitiba (PR), Brasil. E-mail: ernani@ufpr.br

*Autor correspondente 
ocorridos ao longo da evolução tectônica da Bacia Sedimentar do Paraná.

A importância estratégica do SASG é proporcional à dificuldade exploratória (poços com vazões representativas). Cabe ressaltar que foram descritos casos em que dois poços tubulares distantes entre si por menos de dez metros apresentaram capacidades específicas antagônicas. Desta maneira, o entendimento de aspectos geológicos, estruturais e hidrogeológicos reduzem significativamente o risco de perfurações de poços tubulares improdutivos.

No estado do Paraná, o SASG é responsável pelo abastecimento de 300 municípios, mediante 493 poços tubulares profundos. Em 2010, o volume produzido $\left(75.096 .607 \mathrm{~m}^{3}\right)$ representou $60,74 \%$ da água subterrânea captada no estado do Paraná pela Companhia de
Saneamento do Paraná (SANEPAR), o que possibilita o abastecimento potencial de 1.128.773 habitantes (considerando 30\% de perdas no sistema de distribuição).

O objetivo final deste trabalho foi a caracterização do Sistema Aquífero Serra Geral no estado do Paraná, mediante seus aspectos hidrodinâmicos e hidroquímicos regionais. Em específico, dois objetivos são claros:

- Caracterizar o arcabouço estrutural do SASG no estado do Paraná e seu reflexo na hidrogeologia (vazão e capacidade específica) do aquífero;

- Classificar os principais tipos de água, bem como suas aptidões para utilização in natura (consumo humano e irrigação).

\section{Aspectos geológicos regionais do SASG O SASG} está inserido no contexto tectônico da Bacia Sedimentar

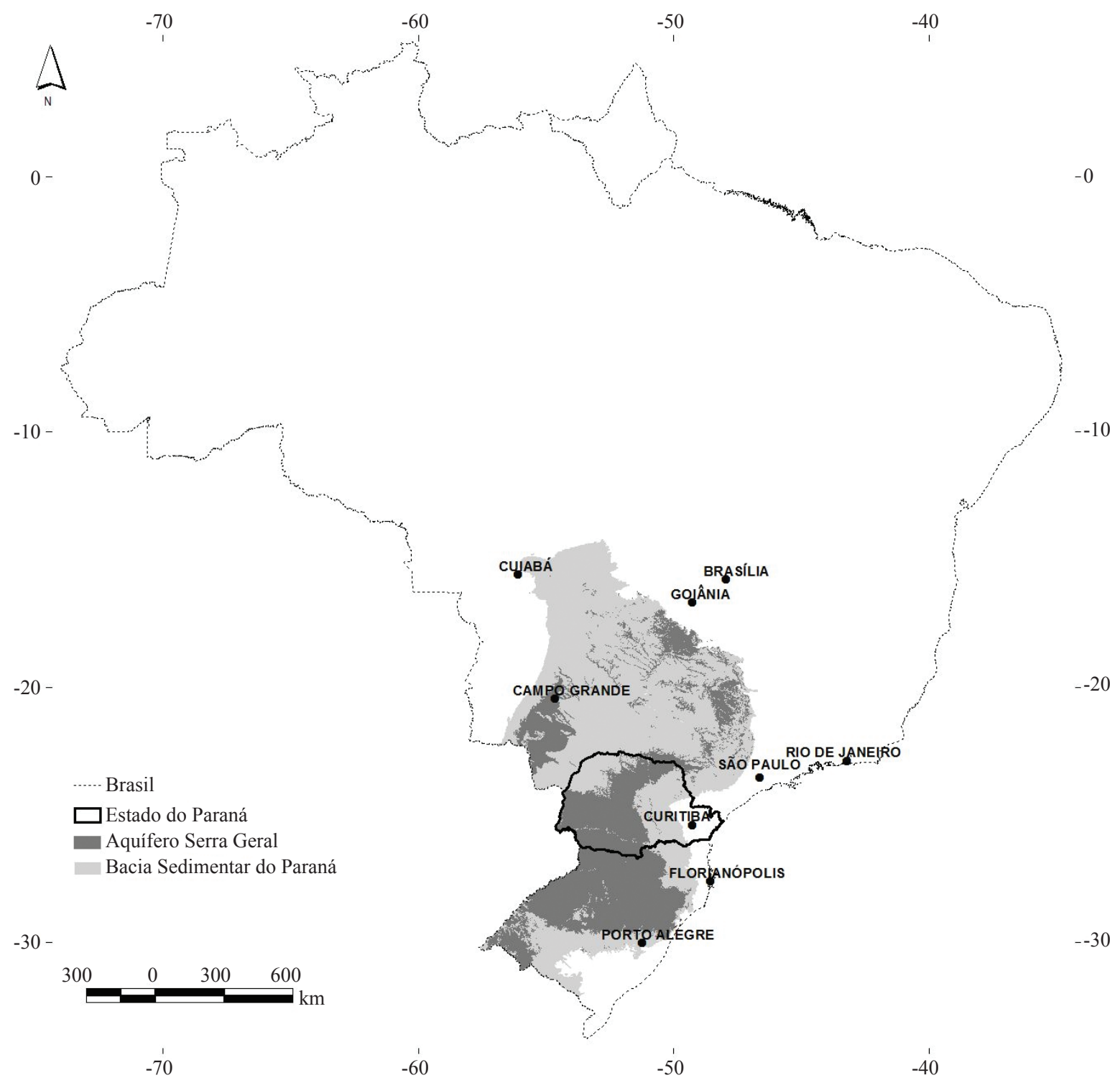

Figura 1 - Localização da Fm. Serra Geral no Brasil e no Paraná. 
do Paraná, recobrindo cerca de $75 \%$ de seu território. A Bacia do Paraná foi classificada por Milani (2004) como Bacia intracratônica, pois "situa-se inteiramente contida na placa sul-americana e não apresenta relacionamento direto com as margens desta placa".

Os derrames possuem textura microcristalina, estrutura maciça e vesicular e/ou amigdaloidal, intenso fraturamento, bem como esfoliações esferoidais. Segundo Melfi et al. (1988), as suítes vulcânicas são essencialmente sub-horizontais, com um mergulho médio de $5^{\circ}$ em direção ao interior da Bacia do Paraná. Entretanto, os fluxos basais podem apresentar inclinações excepcionalmente altas relacionadas à topografia irregular do embasamento.

Thiede \& Vasconcelos (2010) dataram a extrusão das rochas da Fm. Serra Geral pelo método do $\mathrm{Ar} / \mathrm{Ar}$, sugerindo idade de 134,7 $\pm 1 \mathrm{Ma}$. Esses autores relatam que o vulcanismo deu-se em um intervalo $\leq 1,2 \mathrm{Ma}$. Corrobora esse resultado de 'rápida' extrusão, os dados de Renner et al. (1996), que identificaram quatro inversões de campo magnético nesse período.

\section{Aspectos hidrogeológicos regionais do SASG no estado do Paraná Uma abordagem regional} realizada por Rosa Filho \& Hindi (2006) descreve para o SASG, no estado do Paraná, teores de sólidos totais dissolvidos entre 100 e $150 \mathrm{mg} \mathrm{L}^{-1}, \mathrm{pH}$ entre 6,6 a 7,2 e dureza em torno de $40 \mathrm{mg} \mathrm{CaCO}_{3} / \mathrm{L}$. $\mathrm{O}$ teor médio de cálcio é $9 \mathrm{mg} \mathrm{L}^{-1}$. As concentrações de magnésio variam de 3,5 a $6,5 \mathrm{mg} \mathrm{L}^{-1}$, as de sódio, entre 1,2 a $3,7 \mathrm{mg} \mathrm{L}^{-1}$, e as de potássio, entre 1,5 a $3 \mathrm{mg} \mathrm{L}^{-1}$. O teor médio de bicarbonato é $38 \mathrm{mg} \mathrm{L}^{-1}$, o de cloreto, 1,5 $\mathrm{mg} \mathrm{L}^{-1} \mathrm{e}$ o de sulfato, 2,5 $\mathrm{mg} \mathrm{L}^{-1}$.

A SANEPAR abasteceu em 2009 cerca de 1,1 milhões de habitantes com águas do SASG no estado do Paraná, através da operação de 493 poços tubulares. Isso representa $61 \%$ do volume de água subterrânea produzida pela companhia. $\mathrm{O}$ regime de bombeamento dos poços é, em média, de $16 \mathrm{~h} /$ dia, e vazão explotada foi da ordem de $75.096 .607 \mathrm{~m}^{3} /$ ano (Athayde 2010).

Athayde et al. (2007) sugerem a conectividade entre os aquíferos SASG e Sistema Aquífero Guarani (SAG) mediante interpretação de dados potenciométricos e analise hidroquímica de amostras de água coletadas em poços de ambos os aquíferos (SASG e SAG) na região do município de Marechal Cândido Rondon e municípios limítrofes.

MATERIAIS E MÉTODOS Todos os dados adquiridos e gerados durante o desenvolvimento desta pesquisa foram armazenados em um Banco de Dados Georreferenciados permitindo a organização, compilação e integração das informações em diferentes escalas e áreas temáticas.

A investigação é baseada na superposição de mapas transparentes (overlays) e na análise estatística dos dados (Mellanger et al. 1984). Isso está diretamente relacionado com o limite da capacidade humana em combinar os dados necessários para a construção de modelos interpretativos complexos. O tratamento da informação na forma analógica é assim limitado por condicionantes simplórios, tal como a transparência de um conjunto de mapas desenhados em papel vegetal. Além disso, para que a interpretação multivariada de um certo espaço geográfico seja efetiva, é necessário que os dados tabulares sejam espacializados, de modo que se torne clara a regionalização das variáveis relacionadas aos processos investigados (Licht 2001).

Todos os dados georreferenciados, base do sistema de informações georreferenciadas deste estudo, estão projetados em coordenadas geográficas, datum SAD 1969.

Poços tubulares profundos Nesta pesquisa foram consultados 337 poços tubulares profundos utilizados para abastecimento público. Os poços pertencem a SANEPAR, Prefeitura de Marechal Cândido Rondon, Prefeitura de Pato Bragado e Prefeitura de Entre Rios do Oeste.

Nos 337 poços tubulares, foram realizadas amostragens de água para determinação dos principais cátions e ânions, assim como foram determinados em campo os parâmetros: $\mathrm{pH}$, temperatura e condutividade elétrica. A campanha de amostragem dos 337 poços ocorreu entre os anos de 2007 e 2008, vinculadas ao Projeto Rede Sul — Laboratório de Pesquisas Hidrogeológicas (LPH).

Dados, como coordenadas, profundidade do nível estático e dinâmico, vazão, tempo de bombeamento e espessura de solo, foram obtidos junto à ficha construtiva dos poços tubulares e tabelados em planilha eletrônica, compondo o banco de dados do projeto.

Limite do SASG no estado do Paraná Os limites do SASG foram extraídos do Mapa Geológico do Estado do Paraná (MINEROPAR 2006).

Base altimétrica A altimetria do projeto foi realizada a partir dos dados Shuttle Radar Topography 
Mission (SRTM). O Projeto SRTM consiste em parceria entre a National Aeronautics and Space Administration (NASA) e a National Geoespatial Intelligence Agency (NGA).

Essas imagens foram adquiridas no sitio eletrônico do serviço geológico americano (USGS) e após a seleção das imagens correspondentes à área analisada. As imagens foram tratadas com o auxílio dos programas Arcview 3.2 e Global Maper 11. Posteriormente foram inseridas no banco de dados. As especificações técnicas originais destes modelos para download são: datum horizontal - WGS 84; datum vertical - WGS84/EGM96 geoide; projeção geográfica e a unidade vertical em metros.

\section{Análise estatística dos dados hidrogeológicos}

Dados geológicos raramente obedecem a uma distribuição normal ou Gaussiana. Desta forma os resultados foram convertidos para logaritmo antes das análises estatísticas. Ao término das análises, foi calculado o antilogaritmo dos resultados, para ilustrar os mapas e tabelas com valores na unidade de medida do parâmetro analisado e não em logaritmo.

A seguir, foram estudadas as medidas de ordenamento, posição e dispersão. Para facilitar a observação, manipulação e o entendimento dos dados, foram geradas as tabelas de frequências absolutas, relativas e acumuladas, onde a quantidade de classes foi determinada conforme a Fórmula de Sturges, o qual considera como fundamental o número de observações. A amplitude das classes foi calculada segundo a Regra de Lepeltier para distribuições log-normais (assimétricas). É também apresentado o histograma, onde os dados são representados em gráfico de barras verticais, o que permite visualizar tabelas de frequências de uma amostra ou variável.

A análise estatística subsidiou, nesta pesquisa, a confecção das legendas dos mapas apresentados. Dentre os dados analisados e identificados nos mapas temáticos hidrogeológicos, foram considerados valores anômalos aqueles situados acima do terceiro quartil, ou seja, a partir da divisão de uma série ordenada de dados em duas partes, $75 \%$ dos dados são menores e $25 \%$ dos dados são maiores que o terceiro quartil.

\section{Mapa potenciométrico do SASG no estado} do Paraná O mapa potenciométrico do SASG foi confeccionado a partir da diferença entre a altitude da 'boca do poço' (obtida através da altimetria do projeto SRTM) e a profundidade dos níveis estáticos nos 337 poços tubulares profundos.

Cabe ressaltar que as medidas de profundidade do nível estático referem-se a diferentes datas, obtidas quando da perfuração dos poços. Para obtenção de uma medida mais real, seria necessário paralisar o bombeamento em todos os poços, e aguardar a recuperação e estabilização do nível estático, atividade de difícil execução, uma vez que todos os poços aqui analisados são utilizados para abastecimento público.

Dessa forma, e em função de tratar-se de um aquífero fraturado, o mapa potenciométrico apresentado deve ser considerado como uma aproximação virtual da superfície equipotencial do SASG.

Nesse mapa, as linhas equipotenciais (que representam a intersecção da superfície potenciométrica com um plano de cota potenciométrica definida) estão referenciadas em metros sobre o nível do mar (m.s.n.m.).

Posteriormente, a partir do conhecimento do sentido de fluxo do aquífero, foram feitas inferências sobre as áreas de recarga regionais do aquífero.

\section{Vazão de exploração e capacidade específica dos} poços A função de abastecimento público é sem duvida a mais importante dentre as atribuições de um aquífero. Desta maneira, seus poços são dimensionados com câmaras de bombeamento maiores (mínimo de 8") para suportar elevadas vazões e crescentes demandas de abastecimento.

A caracterização da produtividade dos poços do SASG no estado do Paraná é realizada a partir da análise estatística de vazão e capacidade específica dos 337 poços tubulares profundos.

A vazão e o nível dinâmico dos poços referem-se a abril de 2010, representando as condições de exploração dos poços, que em grande parte dos casos, apresentam bombeamentos diários superiores a $15 \mathrm{~h}$. No cálculo da capacidade específica, o nível estático foi obtido mediante consulta nas fichas de perfuração dos poços. A vazão e o rebaixamento utilizados constam do banco de dados supramencionado.

\section{Arcabouço estrutural do SASG paranaense O} arcabouço do SASG foi determinado a partir da integração de dados geofísicos, geológicos e traçados de lineamentos estruturais, os quais serão detalhados a seguir.

ARCABOUÇO AEROMAGNETOMÉTRICO A partir dos dados aeromagnéticos pré-processados, foi aplicado o procedimento de continuação ascendente, 
considerado um filtro de 'limpeza' frequentemente utilizado para remover ou minimizar sinais de fontes rasas e ruídos através da aquisição de dados do campo magnético em níveis superiores ao original.

Foram elaboradas continuações em 1500, 2000 e $3000 \mathrm{~m}$ a partir da grade original de dados e seus respectivos sinais analíticos. Sobre esse mapa foram identificados e traçados os lineamentos regionais do mapa de arcabouço magnético do SASG, o qual será apresentado no capítulo Resultados e Discussões.

Para elaboração do arcabouço magnético-estrutural foram traçados os lineamentos aeromagnetométricos da área em estudo.

A partir dos dados pré-processados, foi aplicado o procedimento de continuação ascendente, considerado um filtro de 'limpeza' e frequentemente utilizado para remover ou minimizar sinais de fontes rasas e ruídos. Este filtro simula a aquisição de dados do campo magnético em níveis superiores ao original. Foram elaboradas continuações em 1500, 2000 e 3000 m a partir dos dados da grade original e seus respectivos sinais analíticos e foram traçados os lineamentos regionais identificados. A integração destes lineamentos resulta no mapa de arcabouço magnético do SASG.

Os procedimentos para obtenção do sinal analítico, bem como das continuações para cima, foram executados com o programa Oásis MontajTM Pacote MAGMAP. Todos os métodos de processamento utilizados encontram-se detalhados em Portela Filho et al. (2002).

ARCABOUÇO ESTRUTURAL DO TOPO DO SISTEMA AQUÍFERO GUARANI Soares et al. (2007) propõe um novo mapa de lineamentos estruturais para o SAG, interpretado a partir de um modelo digital de terreno, de poços de petróleo e poços tubulares profundos. As estruturas foram mapeadas desde a Fm. Irati, época de máxima inundação da bacia sedimentar, até o topo da Fm. Botucatu, representando estruturas tectônicas com implicação na deposição e no fluxo do SAG.

Neste trabalho de pesquisa foram selecionadas as estruturas tectônicas identificadas por Soares et al. (2007), 'recortadas' para o estado do Paraná, na área de ocorrência do SASG.

Os lineamentos traçados por Soares et al. (2007) que recobrem o território paranaense são apresentados na Fig. 2.

TRAÇADO DE LINEAMENTOSO pressuposto que fundamenta esta análise são os lineamentos estruturais. O'Leary et al. (1976) definiram lineamento

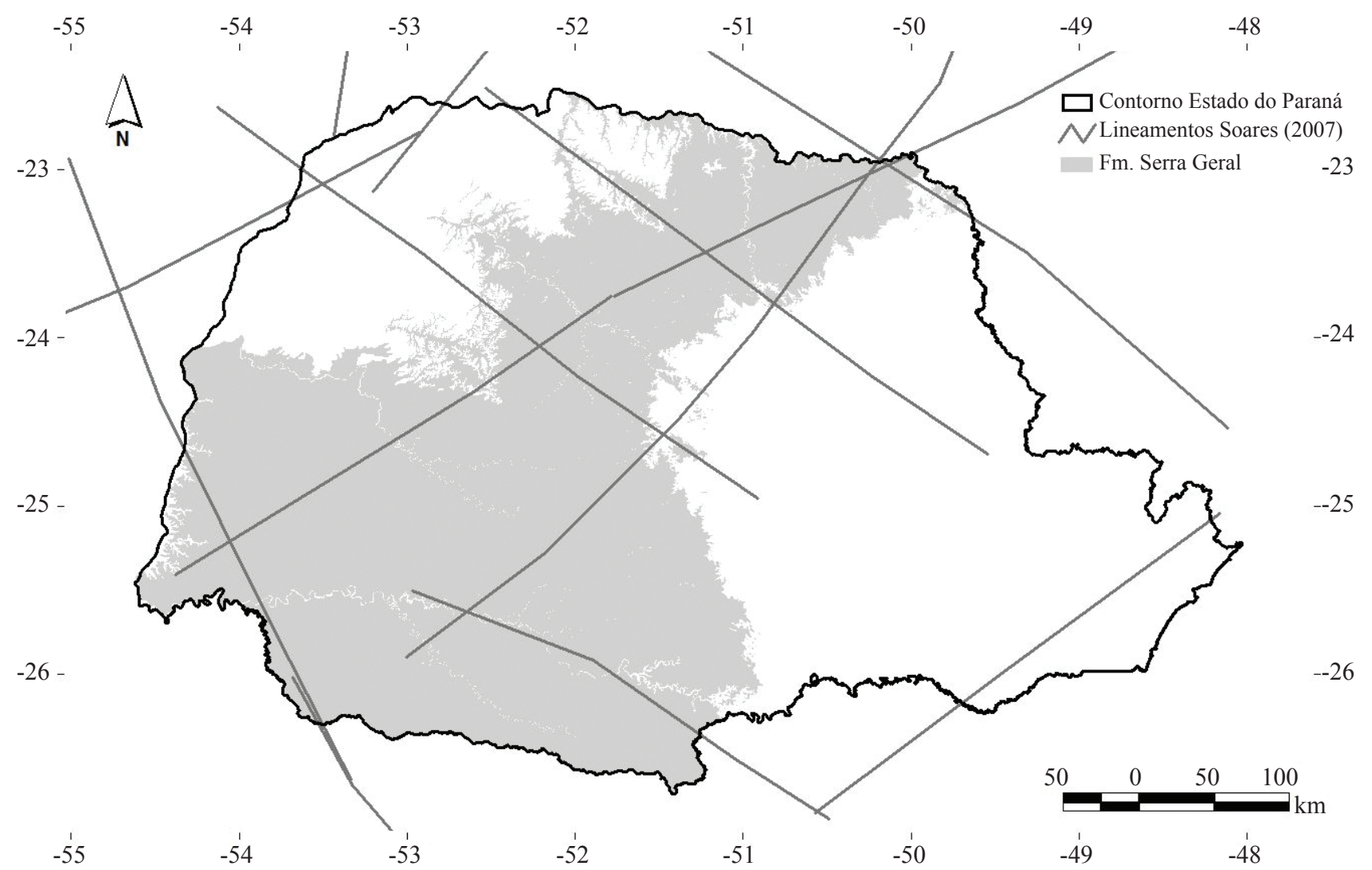

Figura 2 - Lineamentos extraídos do contorno estrutural do topo da Fm. Botucatu de Soares et al. (2007), 'recortados' para o estado do Paraná. 
como sendo uma feição da superfície terrestre que é 'linear', mapeável, simples ou composta, contínua ou descontínua, cujas partes estão alinhadas em um arranjo retilíneo ou suavemente curvo e que difere distintivamente dos padrões de feições adjacentes.

Os lineamentos estruturais foram traçados sobre modelo digital do terreno, utilizando a base altimétrica do projeto SRTM.

Para a realização dos traçados dos lineamentos, utilizou-se nas imagens quatro pseudoiluminações, com as seguintes direções azimutais $45,315,0$ e $90^{\circ}$, apenas lineamentos identificados em todas as iluminações são traçados. Foram traçados lineamentos para toda área de afloramento do SASG paranaense, em duas escalas, 1:2.500.000 (199 lineamentos) e 1:600.000 (1.554 lineamentos).

\section{Províncias Hidroestruturais e Compartimentos} Hidroestruturais A análise de dados geofísicos, geológicos e estruturais possibilitou a delimitação de duas Províncias Hidroestruturais no Sistema Aquífero Serra Geral no estado do Paraná, com a subdivisão de compartimentos hidroestruturais potenciais para a circulação e o armazenamento de água subterrânea.

Províncias Hidroestruturais, neste trabalho, representam delimitações regionais da produtividade do aquífero (mediante análises estatísticas da vazão e capacidade específica dos poços), cujos limites são representados por lineamentos regionais do arcabouço estrutural.

Compartimentos Hidroestruturais são áreas delimitadas por estruturas do arcabouço estrutural do aquífero, em escala de maior detalhe, subdividindo, dessa maneira, as Províncias Hidroestruturais.

\section{Análise hidroquímica do SASG no estado do} Paraná Os laudos analíticos do LPH utilizados nesta pesquisa apresentam 32 parâmetros. A consistência e qualidade dos dados foram avaliadas com base na diferença de balanço iônico (DBI), que mede a diferença relativa entre as concentrações de cátions e ânions, expressa em miliequivalentes por litro (meq $\left.\mathrm{L}^{-1}\right)$.

Após a transformação dos dados de $\mathrm{mg} \mathrm{L}^{-1}$ para meq $\mathrm{L}^{-1}$ com obtenção da DBI (máximo aceito de $10 \%$ ), foram calculadas as porcentagens relativas de cada variável hidroquímica para determinar a tipologia das águas, com base na predominância dos cátions e ânions principais.

Os tipos de água foram determinados inicialmente com base na presença de mais de $50 \%$ dos compostos químicos. As águas cujos compostos químicos não atinjam $50 \%$, são denominadas pelos compostos químicos que apresentaram as duas maiores porcentagens. A classificação química da água foi apresentada graficamente utilizando-se o diagrama de Piper (Piper 1944).

COMPARAÇÃO DOS VALORES OBTIDOS NAS ANÁLISES COM VALORES MÁXIMOS PERMITIDOS (VMP) PARA ÁGUA SUBTERRÂNEA

Os valores obtidos nas análises físico-químicas das águas foram comparados aos valores de referências decretados na Portaria MS 2914/11, a qual dispõe sobre os procedimentos de controle e de vigilância da qualidade da água para consumo humano e seu padrão de potabilidade (Brasil 2011).

\section{CLASSIFICAÇÃO DA ÁGUA PARA IRRIGAÇÃO}

$\mathrm{O}$ uso da água subterrânea para irrigação é limitado pelos efeitos adversos ao solo e plantas, relacionados à presença de substâncias dissolvidas na água, associados à salinidade total da água e ao conteúdo de sódio em solução.

A irrigação com água contendo quantidades significativas de $\mathrm{Na}^{+}$causa o 'risco de sódio', devido aos efeitos deste íon no solo. O sódio é adsorvido pelas partículas do solo, tornando-o duro e compacto quando seco e impermeável à percolação da água. Os solos de textura fina, com alto conteúdo de argila são os mais susceptíveis aos efeitos do sódio. A presença de $\mathrm{Ca}^{2+}$ e $\mathrm{Mg}^{2+}$ em altas concentrações no solo ajudam a controlar os efeitos do sódio e a manter as propriedades texturais e estruturais deste.

$\mathrm{O}$ risco do sódio é expresso em termos de sodium adsorption ratio (SAR), que compara as concentrações de $\mathrm{Na}^{+}, \mathrm{Ca}^{2+} \mathrm{e} \mathrm{Mg}^{2+}$ na água.

Para a avaliação da qualidade da água para fins de irrigação, os dados foram plotados no diagrama que relaciona a razão de adsorção de sódio (RAS) com a condutividade elétrica da água, desenvolvido pelo U.S. Salinity Staff (1954), indicando os riscos potenciais de sódio e salinidade.

\section{RESULTADOS E DISCUSSÕES}

\section{Potenciometria e direção de fluxo do SASG}

A análise das linhas equipotenciais traçadas para o SASG permitiu identificar a coincidência geográfica entre os divisores de água superficiais e subterrâneos. Desta forma, assemelham-se aos limites das Bacias Hidrográficas Superficiais (SUDERHSA 2007) e das 
Bacias Hidrogeológicas que compõem o SASG do estado do Paraná. Tal fato corrobora a caracterização do SASG como aquífero livre, uma vez que a topografia do nível estático do aquífero acompanha, em geral, o contorno da superfície do terreno.

Ocorrências de poços com jorrância natural intermitente (principalmente nas zonas de descarga do aquífero) estão relacionados à saturação das áreas de recarga, devido a períodos contínuos de elevada precipitação e recarga do aquífero.

Considerando toda extensão do SASG no estado do Paraná, o fluxo subterrâneo em escala regional dá-se de leste para oeste. O fluxo possui sentido às áreas de descarga situadas nas regiões oeste e noroeste paranaense, junto aos rios Paraná (principal área de descarga regional do SASG) e Paranapanema, respectivamente. É possível que a direção de escoamento subterrâneo esteja influenciada pela direção de mergulho regional da Formação Serra Geral no estado do Paraná (direção E-W).

A Fig. 3 apresenta o mapa potenciométrico do SASG no estado do Paraná, com indicação dos sentidos de fluxo. Ressalta-se que em função do SASG ser um aquífero fraturado, as linhas potenciométricas apresentadas em mapa são 'virtuais'.

\section{Vazão de produção dos poços tubulares}

A média geométrica dos valores de vazão dos 337 poços tubulares é igual a $21,5 \mathrm{~m}^{3} \mathrm{~h}^{-1}$, com desvio padrão geométrico de $1,2 \mathrm{~m}^{3} \mathrm{~h}^{-1}$ e coeficiente de variação de $5,7 \%$. O histograma e gráfico com os dados do elemento, os intervalos de um, dois e três desvios geométricos ao redor da média, e a identificação do primeiro, segundo e terceiro quartis são mostrados na Tab. 1. A distribuição espacial do parâmetro analisado é apresentada na Fig. 4.

\section{Capacidade específica dos poços tubulares A} média geométrica dos valores de capacidade específica dos 337 poços tubulares é igual a $1,5 \mathrm{~m}^{3} \mathrm{~h}^{-1} / \mathrm{m}$, com desvio padrão de $1,7 \mathrm{~m}^{3} \mathrm{~h}^{-1} / \mathrm{m}$ e coeficiente de variação de 111,7\%. O histograma deste elemento, o gráfico com os intervalos geométricos ao redor da média, e a identificação do primeiro, segundo e terceiro quartis são mostrados na Tab. 2. A distribuição espacial do parâmetro analisado é apresentada na Fig. 5.

\section{Arcabouço estrutural do SASG no estado do} Paraná A combinação dos mapas lineamentos aeromagnetométricos e lineamentos estruturais de superfície, obtidos através do modelo SRTM, traçado em duas escalas de observações (1:2.500.000 e 1:600.000), corroborado pelas estruturas traçadas por Soares et al. (2007), possibilitou identificar estruturas geológicas regionais, profundas e superficiais, que apresentam continuidade e registro no SASG.

São apresentados de forma sequencial os resultados dos traçados estruturais nos diferentes mapas

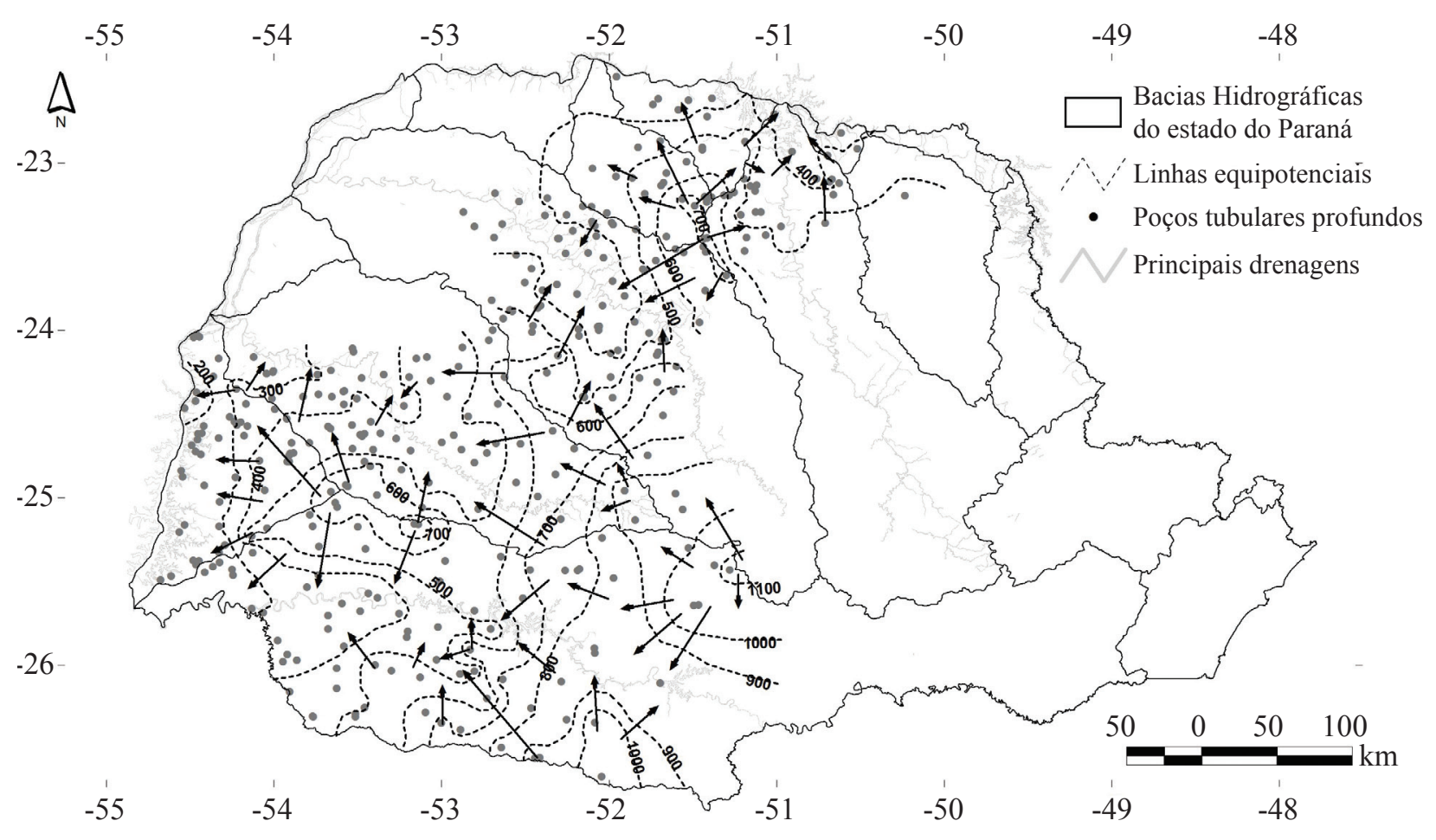

Figura 3 - Mapa potenciométrico do Sistema Aquifero Serra Geral no estado do Paraná. 
Tabela 1 - Estatística univariada dos valores de vazão $\left(m^{3} h^{-1}\right)$

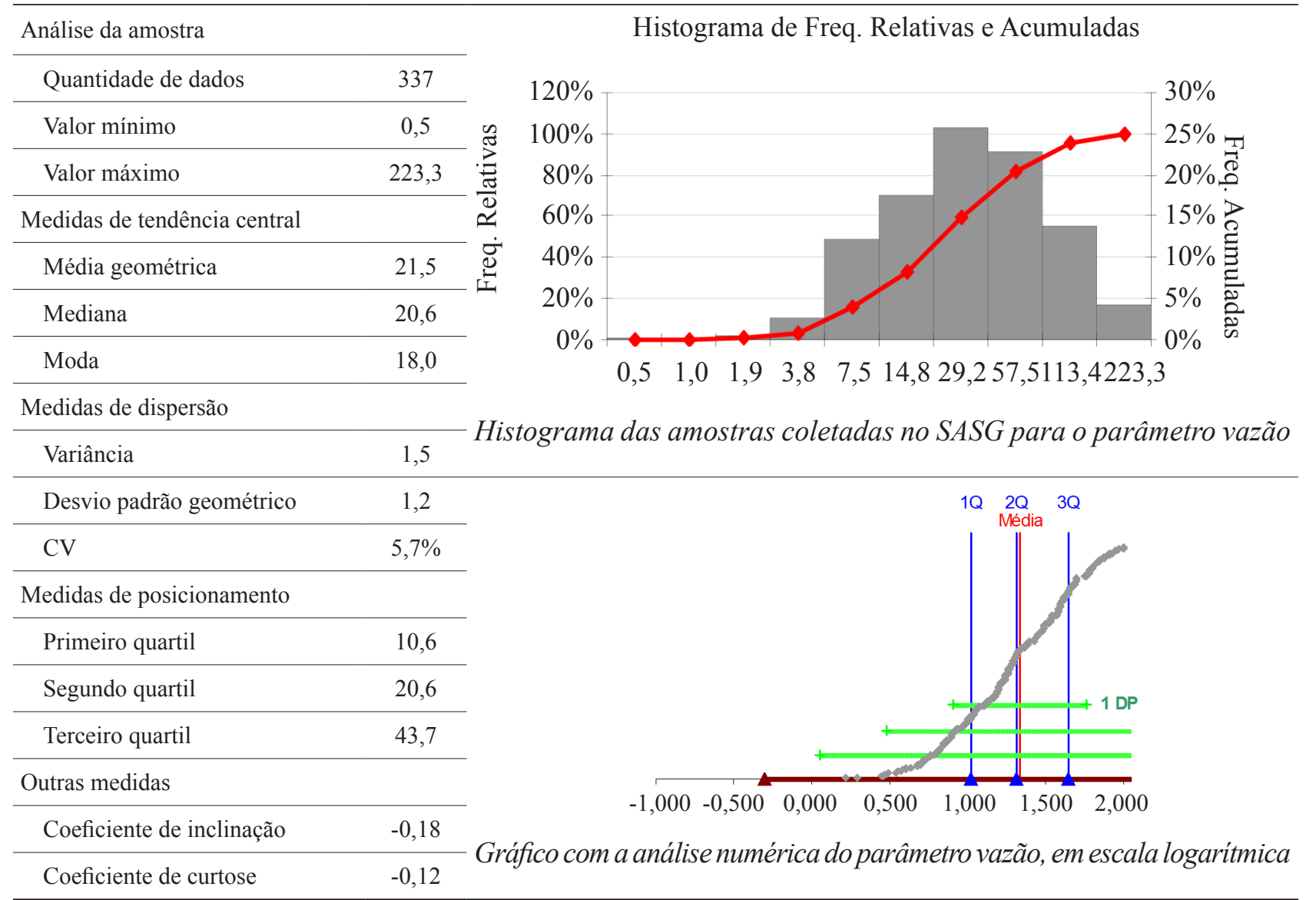

Freq: frequência; SASG: Sistema Aquífero Serra Geral; CV: coeficiente de variação Q: quartil.

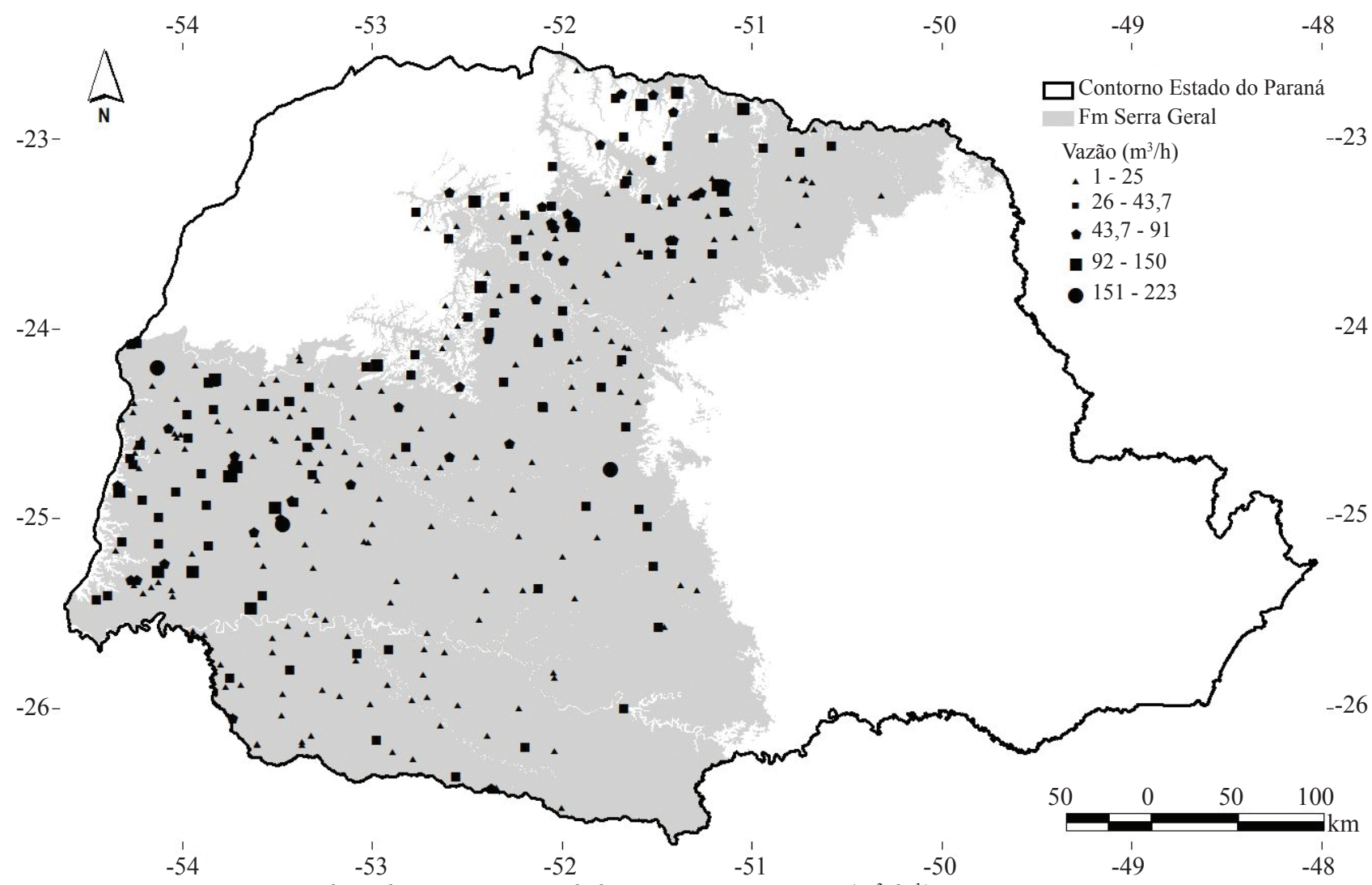

Figura 4 - Mapa com a distribuição espacial do parâmetro vazão $\left(m^{3} h^{-1}\right)$. 
Tabela 2 - Estatística univariada dos valores de capacidade especifica $\left(\mathrm{m}^{3} \mathrm{~h}^{-1} / \mathrm{m}\right)$

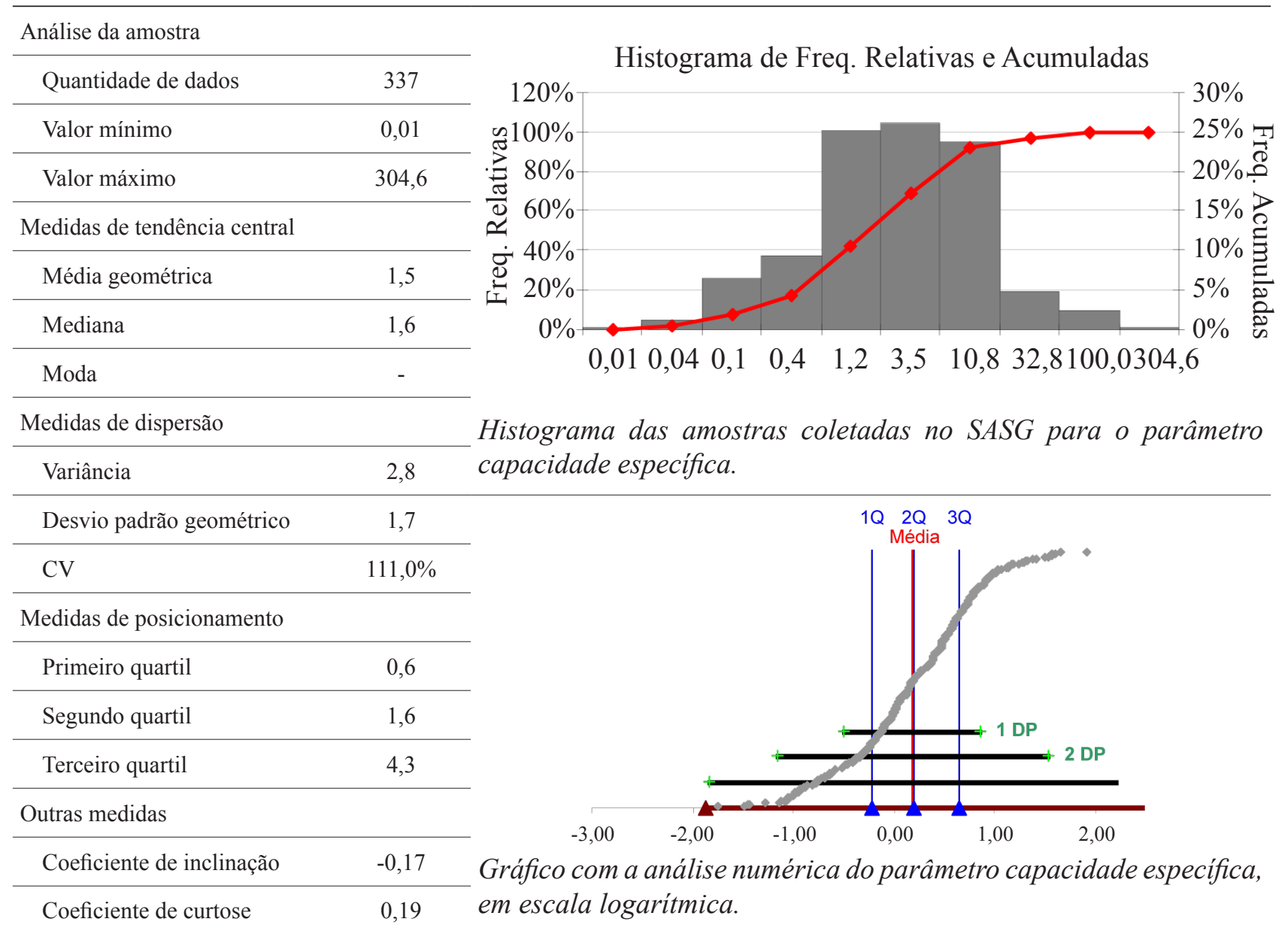

Freq: frequência; SASG: Sistema Aquífero Serra Geral; CV:coeficiente de variação ; Q: quartil.

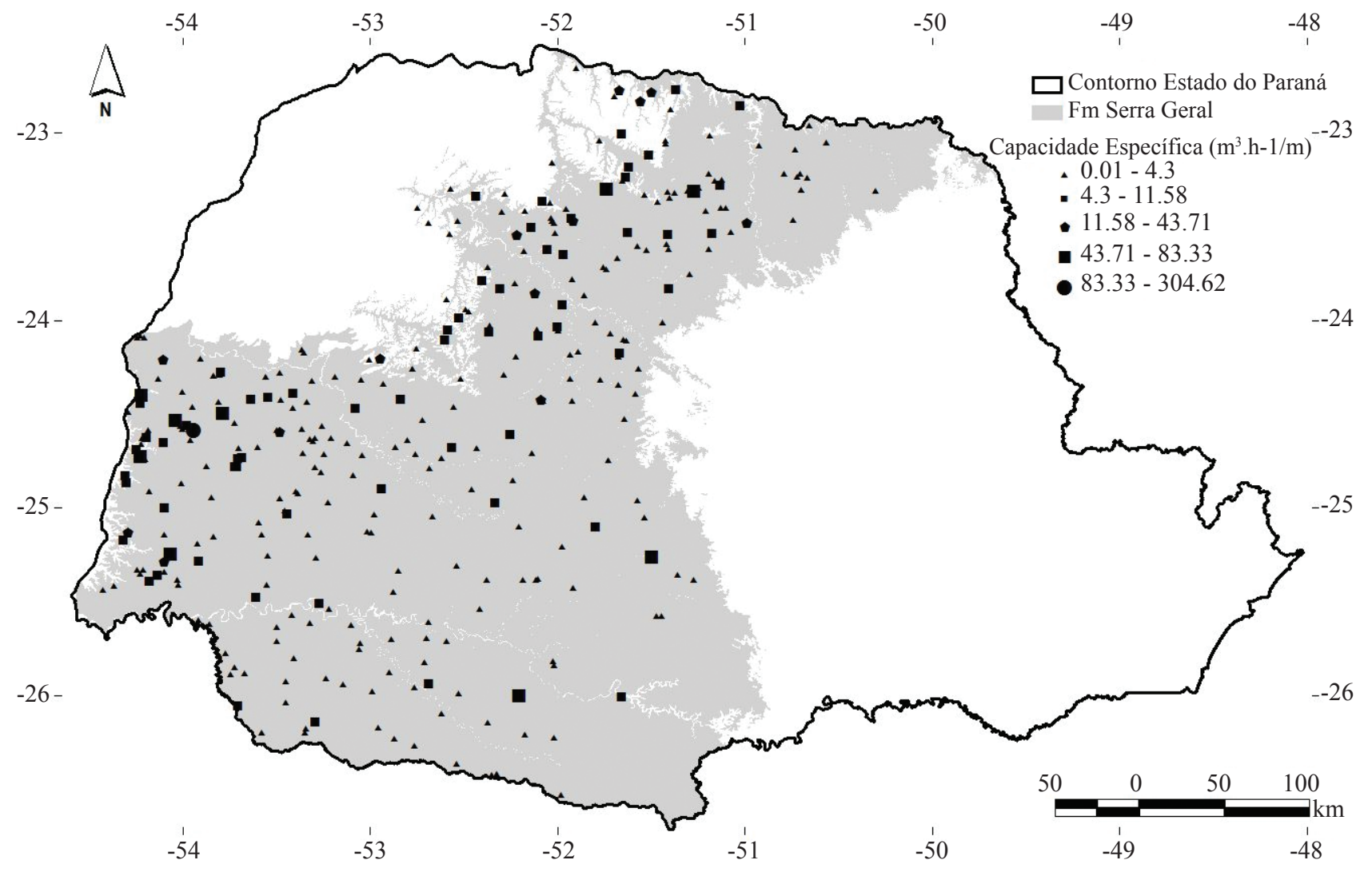

Figura 5-Mapa com a distribuição espacial do parâmetro capacidade especifica $\left(\mathrm{m}^{3} \mathrm{~h}^{-1} / \mathrm{m}\right)$. 
temáticos, culminando ao fim, no traçado de lineamentos que caracterizou o arcabouço estrutural do SASG.

A Fig. 6 destaca o mapa de lineamentos interpretados a partir dos dados aeromagnetométricos. Estruturas de grande continuidade com direção NE e NW são detectadas, refletindo a sobreposição dos eventos tectônicos deformacionais na Bacia do Paraná.

Com o auxílio do modelo SRTM, foram traçados lineamentos para toda a área do SASG em duas escalas de observações; 1:2.500.000 e 1:600.000.

$\mathrm{Na}$ escala de traçado 1:2.500.000 (Fig. 7), observa-se o 'detalhamento' das estruturas regionais apresentadas nos mapas: aeromagnético e Soares et al. (2007), os quais refletem estruturas profundas soto-postas à Formação Serra Geral.

A sobreposição de estruturas profundas (maiores do que um quilômetro) com lineamentos traçados na superfície do SASG é um forte indício da reativação destas durante e/ou após a deposição das rochas vulcânicas da Fm. Serra Geral.

Para maior refinamento dos traçados, optou-se por uma escala de visualização de 1:600.000. Neste mapa podem ser identificados feixes de lineamentos, lineamentos contínuos, e um detalhe ainda maior das estruturas. A Fig. 8 ilustra o mapa dos lineamentos traçados na escala 1:600.000.
O arcabouço estrutural do SASG é apresentado na Fig. 9, onde estão representadas as estruturas com maior continuidade e persistência.

Nota-se que grande parte dos lineamentos com direção NW são coincidentes com as principais drenagens do estado. As estruturas NW são relacionadas à proximidade do SASG, no estado do Paraná, ao Arco de Ponta Grossa. Os lineamentos NE destacam-se por apresentarem-se, de maneira geral, perpendicularmente às grandes drenagens e paralelismo às estruturas do embasamento da Bacia Sedimentar do Paraná. Destacam-se os lineamentos de direção NE, relacionados à direção Jacutinga-Guaxupé.

\section{Províncias Hidroestruturais do SASG no estado} do Paraná A distribuição das vazões e capacidades específicas dos poços utilizados nesta pesquisa mostrou que os valores obtidos não se distribuem ao acaso, ocorrendo mediante controle estrutural em zonas (ou compartimentos estruturais) com maiores e menores vazões.

A subdivisão aqui proposta (Figs. 10 e 11) para os parâmetros vazão e capacidade especifica, respectivamente, separa o SASG em duas províncias, a noroeste e sudeste da Falha de Jacutinga, modificando a proposta de Fraga (1986) de subdivisão do SASG mediante o limite da Bacia Hidrográfica do Iguaçu

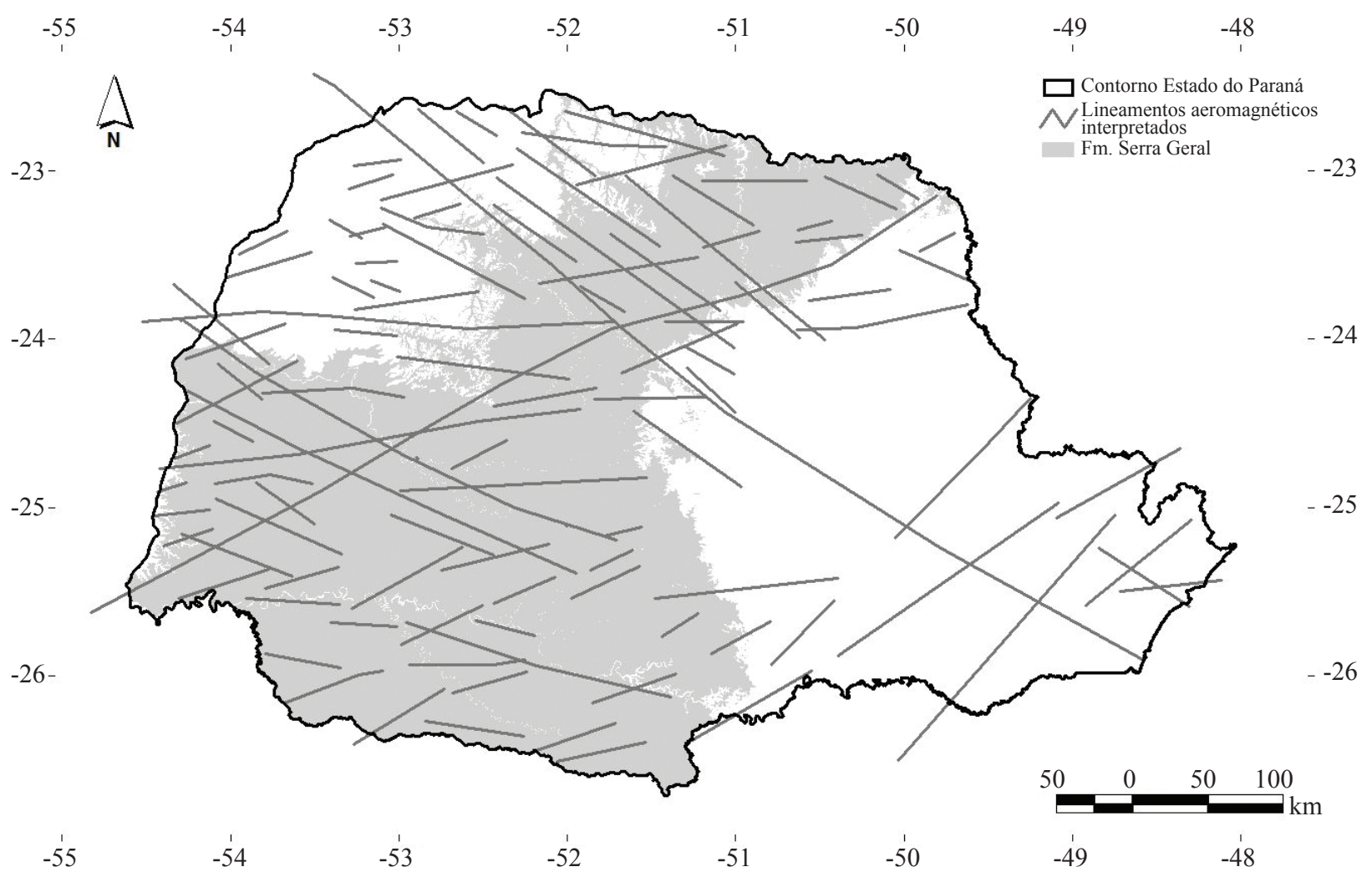

Figura 6 - Lineamentos aeromagnéticos interpretados. 


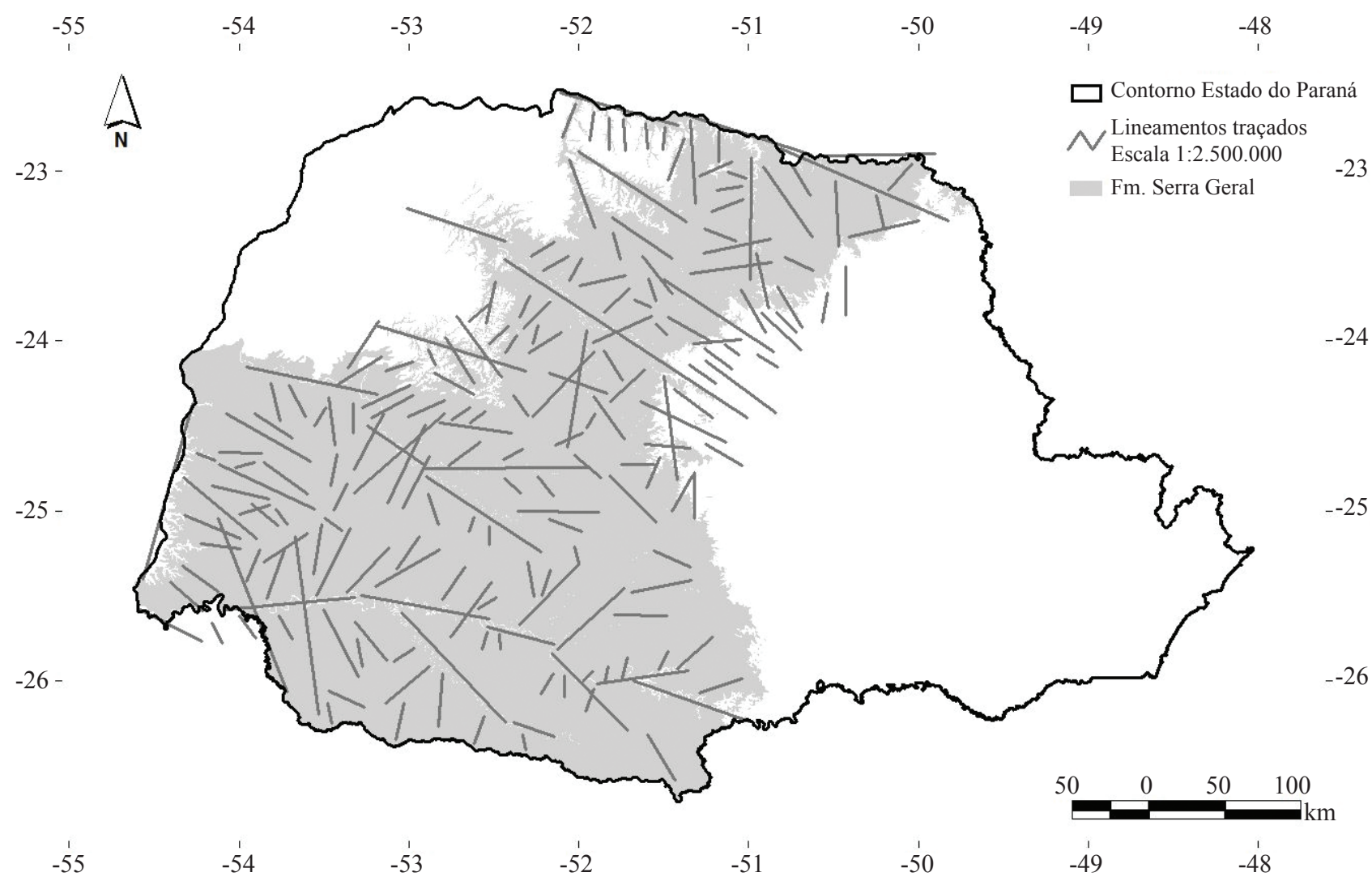

Figura 7 -Lineamentos traçados escala 1:2.500.000.

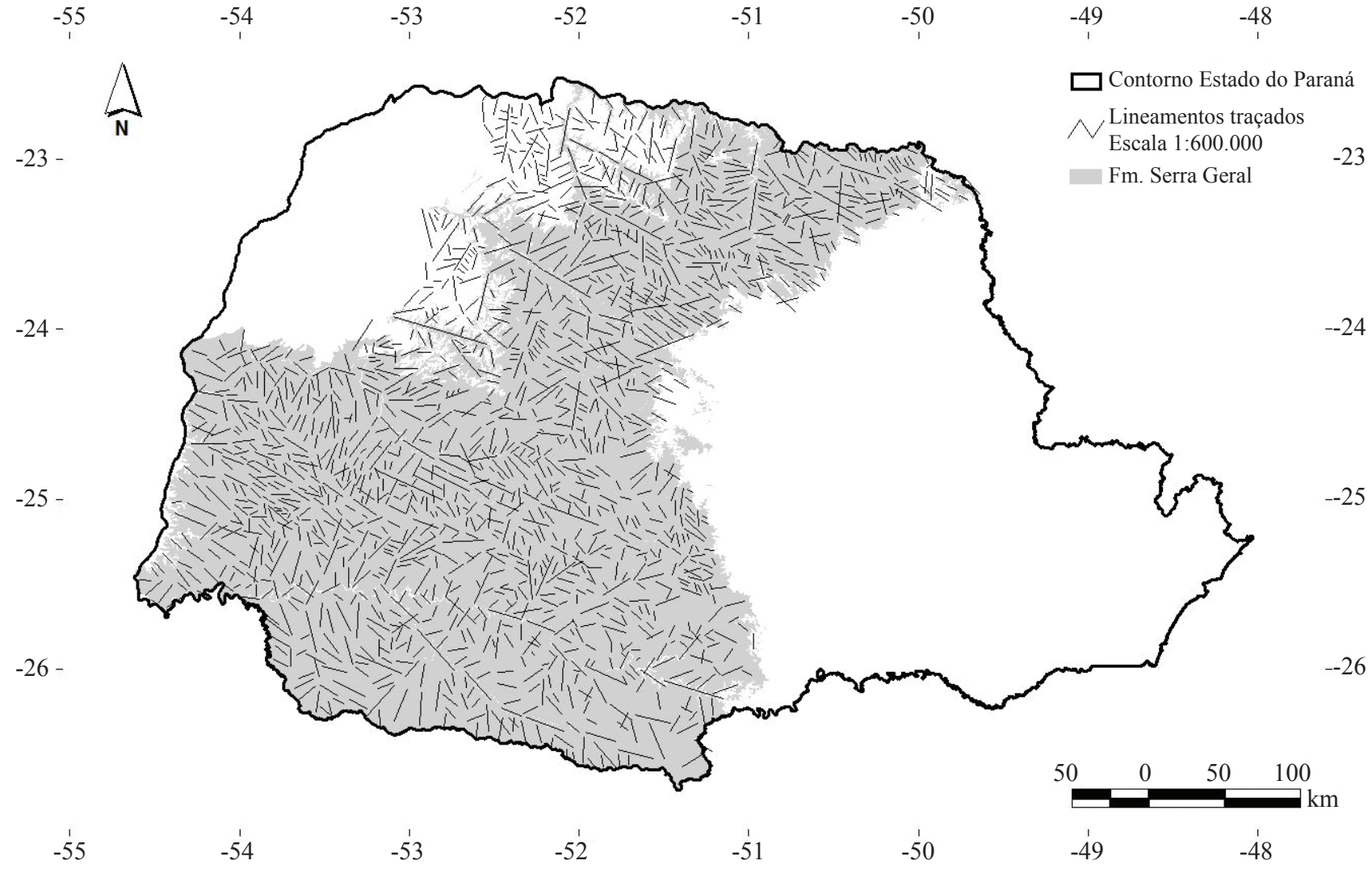

Figura 8-Lineamentos traçados escala 1:600.000. 


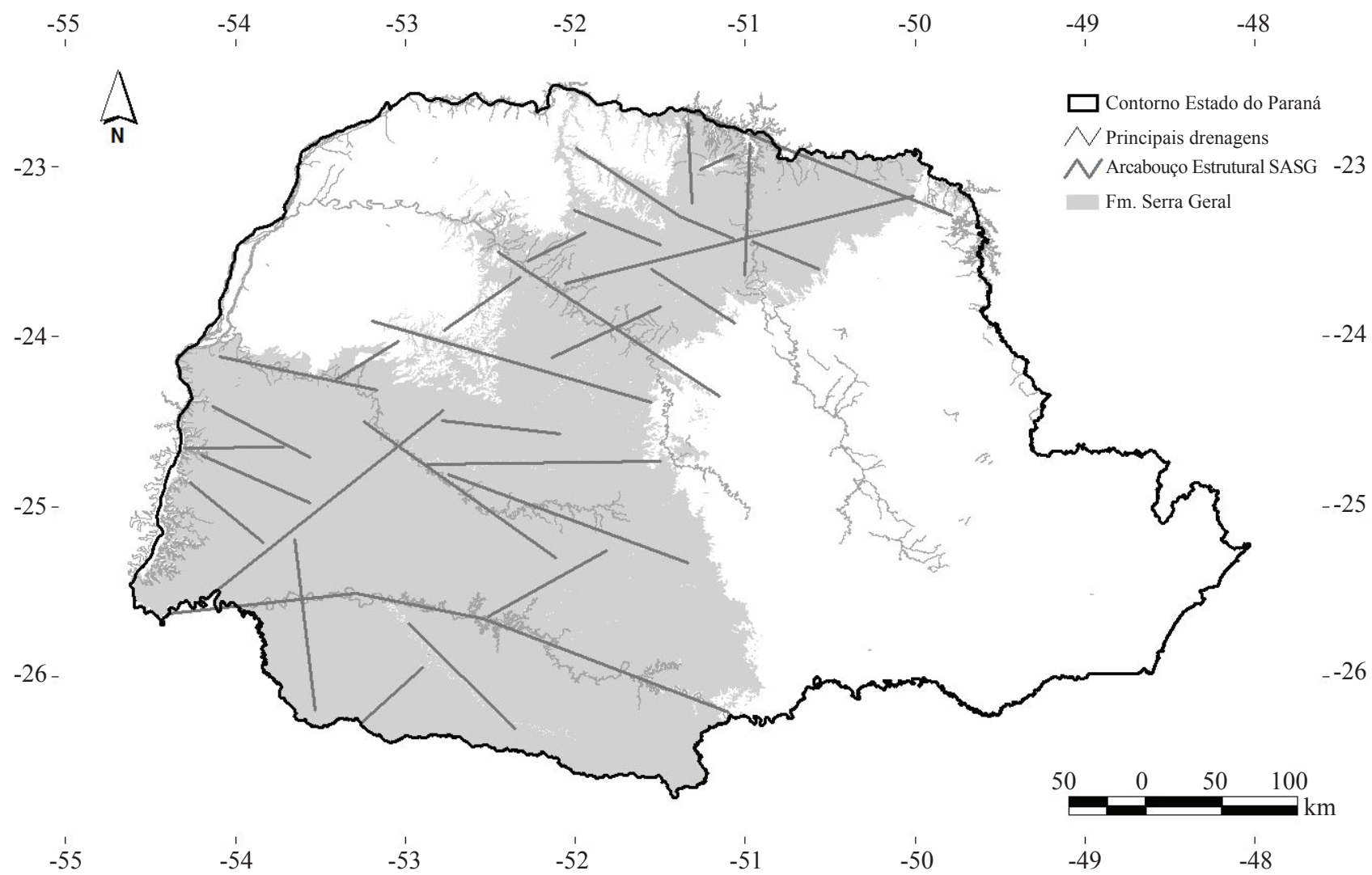

Figura 9 - Arcabouço estrutural do Sistema Aquífero Serra Geral no estado do Paraná.

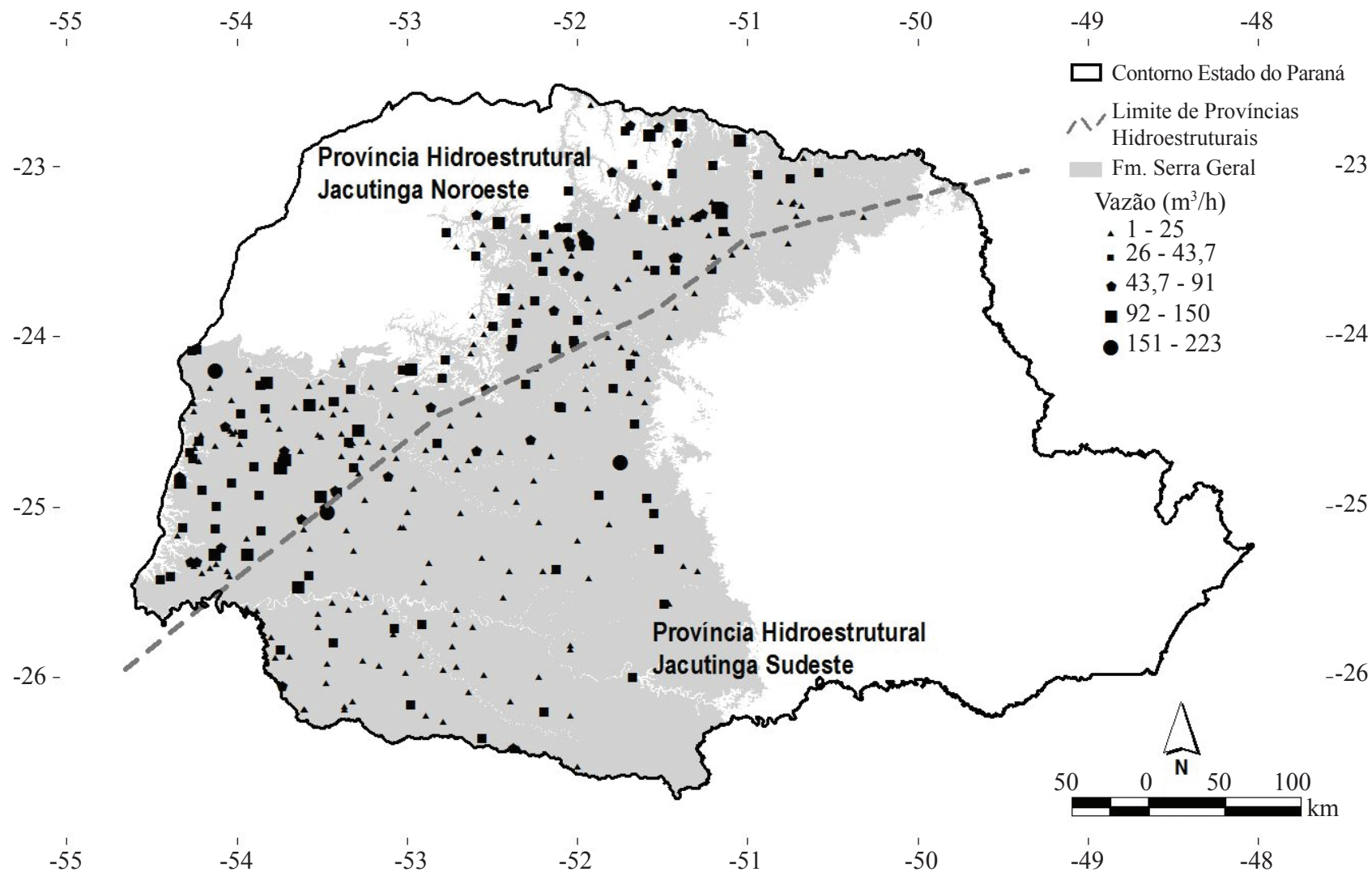

Figura 10 - Províncias Hidroestruturais do Sistema Aquifero Serra Geral no estado do Paraná considerando o parâmetro vazão. 
Poços tubulares situados no Compartimento Hidroestrutural Jacutinga Noroeste apresentam vazões e capacidades específicas superiores (valores acima do terceiro quartil), quando comparado aos poços situados no Compartimento Hidroestrutural Jacutinga Sudeste (Tab. 3).

\section{Compartimentos Hidroestruturais do SASG no} estado do Paraná A partir da caracterização das duas Províncias Hidroestruturais foram delimitados quatro 'Compartimentos Hidroestruturais' (Fig. 12). O limite de cada Compartimento Hidroestrutural coincide com o arcabouço estrutural proposto ao SASG.

O Compartimento Maringá está localizado no norte pioneiro paranaense, limitado a sul pelo rio Ivaí e a norte pelo rio Paranapanema. Predominam lineamentos (405 traçados) com direção N50W a N60W, seguidos por N60W a N70W, observados na escala 1:600.000. Nesta província estão localizados os enxames de diques relacionados ao Arco de Ponta Grossa. Poços tubulares situados nesta província apresentam mediana de vazão de $31 \mathrm{~m}^{3} \mathrm{~h}^{-1}$ e mediana da capacidade específica $2,38 \mathrm{~m}^{3} \mathrm{~h}^{-1} \mathrm{~m}^{-1}$. Trata-se do compartimento com melhor produtividade (capacidade específica) do SASG.

O Compartimento Campo Mourão está localizado no centro do estado do Paraná, limitado a norte pelo lineamento onde está 'encaixado' o rio Ivaí, a sul por um grande lineamento lesteoeste e a sudoeste pelo rio Piquiri. Predominam lineamentos (278 traçados) com direção N50W

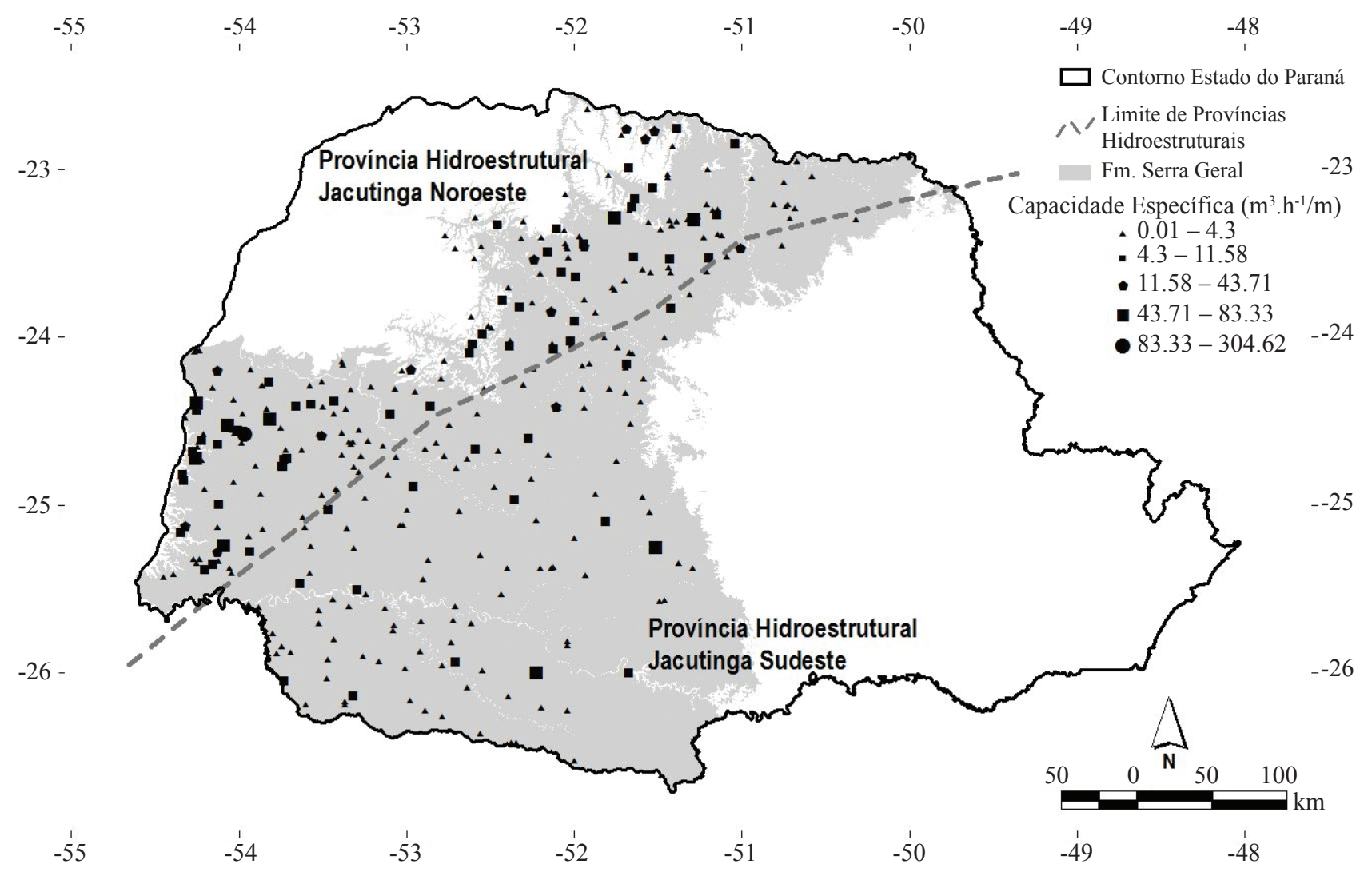

Figura 11 - Províncias Hidroestruturais do Sistema Aquífero Serra Geral no estado do Paraná, considerando o parâmetro capacidade específica.

Tabela 3 - Comparação estatística entre as Províncias Hidroestruturais Jacutinga Noroeste e Sudoeste

\begin{tabular}{lcccc}
\hline \multirow{2}{*}{ Parâmetros } & Província Hidroestrutural Jacutinga Noroeste & \multicolumn{2}{c}{ Província Hidroestrutural Jacutinga Sudeste } \\
\cline { 2 - 5 } & $\begin{array}{c}\text { Vazão } \\
\left(\mathrm{m}^{3} \mathrm{~h}^{-1}\right)\end{array}$ & $\begin{array}{c}\text { Cap esp. } \\
\left(\mathrm{m}^{3} \mathrm{~h}^{-1} \mathrm{~m}^{-1}\right)\end{array}$ & $\begin{array}{c}\text { Vazão } \\
\left(\mathrm{m}^{3} \mathrm{~h}^{-1}\right)\end{array}$ & $\begin{array}{c}\text { Cap esp. } \\
\left(\mathrm{m}^{3} \mathrm{~h}^{-1} \mathrm{~m}^{-1}\right)\end{array}$ \\
\hline Valor máximo & 198 & 304 & 223 & 34,82 \\
\hline Valor mínimo & 3 & 0,02 & 0,5 & 0,01 \\
\hline Mediana & 31,5 & 2,5 & 13 & 0,9 \\
\hline Moda & 17 & 0,21 & 29,6 & 0,09 \\
\hline Desvio padrão & 34,7 & 22,9 & & 128 \\
\hline Número de poços & & 209 & &
\end{tabular}

Cap esp.: capacidade específica. 
a N60W, seguidos por N40W a N50W, quando observados na escala 1:600.000. Poços tubulares situados nesta província apresentam mediana de vazão de $19 \mathrm{~m}^{3} \mathrm{~h}^{-1}$ e mediana da capacidade específica $2,08 \mathrm{~m}^{3} \mathrm{~h}^{-1} \mathrm{~m}^{-1}$.

O Compartimento Foz do Iguaçu está localizado no oeste paranaense, limitado a sudeste por um grande lineamento com direção NE (corresponde ao limite entre as Bacias Hidrográficas do Paraná 3 e do Iguaçu), a norte pelo rio Piquiri e a oeste pelo Reservatório de Itaipu Binacional (Rio Paraná). Predominam lineamentos (226 traçados) com direção N50W a N60W, seguidos por $\mathrm{N} 40 \mathrm{~W}$ a $\mathrm{N} 50 \mathrm{~W}$, quando considerados os traçados na escala 1:600.000. Poços tubulares situados nesta província apresentam mediana de vazão de $33 \mathrm{~m}^{3} \mathrm{~h}^{-1}$ e mediana da capacidade específica $2,08 \mathrm{~m}^{3} \mathrm{~h}^{-1} \mathrm{~m}^{-1}$.

O Compartimento Foz do Areia é o com maior área dentre os compartimentos definidos neste trabalho. Está localizado no sudoeste paranaense, limitado a noroeste por um grande lineamento com direção NE (corresponde ao limite entre as Bacias Hidrográficas do Paraná 3 e do Iguaçu), a norte por um lineamento leste-oeste de dimensão regional, e a sul faz limite com o estado de Santa Catarina. Predominam lineamentos (616 traçados) com direção N60W a N70W, seguidos por N50W a $\mathrm{N} 60 \mathrm{~W}$, quando considerados os traçados na escala 1:600.000. Poços tubulares situados nesta província apresentam mediana de vazão de $14,5 \mathrm{~m}^{3} \mathrm{~h}^{-1} \mathrm{e}$ mediana da capacidade específica $0,90 \mathrm{~m}^{3} \mathrm{~h}^{-1} \mathrm{~m}^{-1}$. Trata-se da província com pior índice de produtividade do SASG.

A Tab. 4 apresenta a análise estatística da capacidade específica dos poços tubulares profundos separados por compartimentos hidroestruturais.

Análise hidroquímica A análise dos resultados das amostras coletadas em 337 poços tubulares que captam o SASG permitiu classificar 12 tipos de água. A Fig. 13 apresenta o Diagrama de Piper das amostras coletadas no SASG.

Quatro grandes grupos de água foram classificados dentre as 337 amostras coletadas: águas tipo bicarbonatadas, tipo carbonatadas, águas tipo sulfatadas e tipo nitratada.

Predominaram águas do tipo bicarbonatadacálcica (198 amostras); secundariamente águas do tipo bicarbonatada-sódica (50 amostras); seguidas por águas bicarbonatadas cálcio-magnesianas (25 amostras), carbonatada sódica (23 amostras), bicarbonatada-cálcio sódica (19 amostras), bicarbonatada sódio cálcicas (13 amostras).

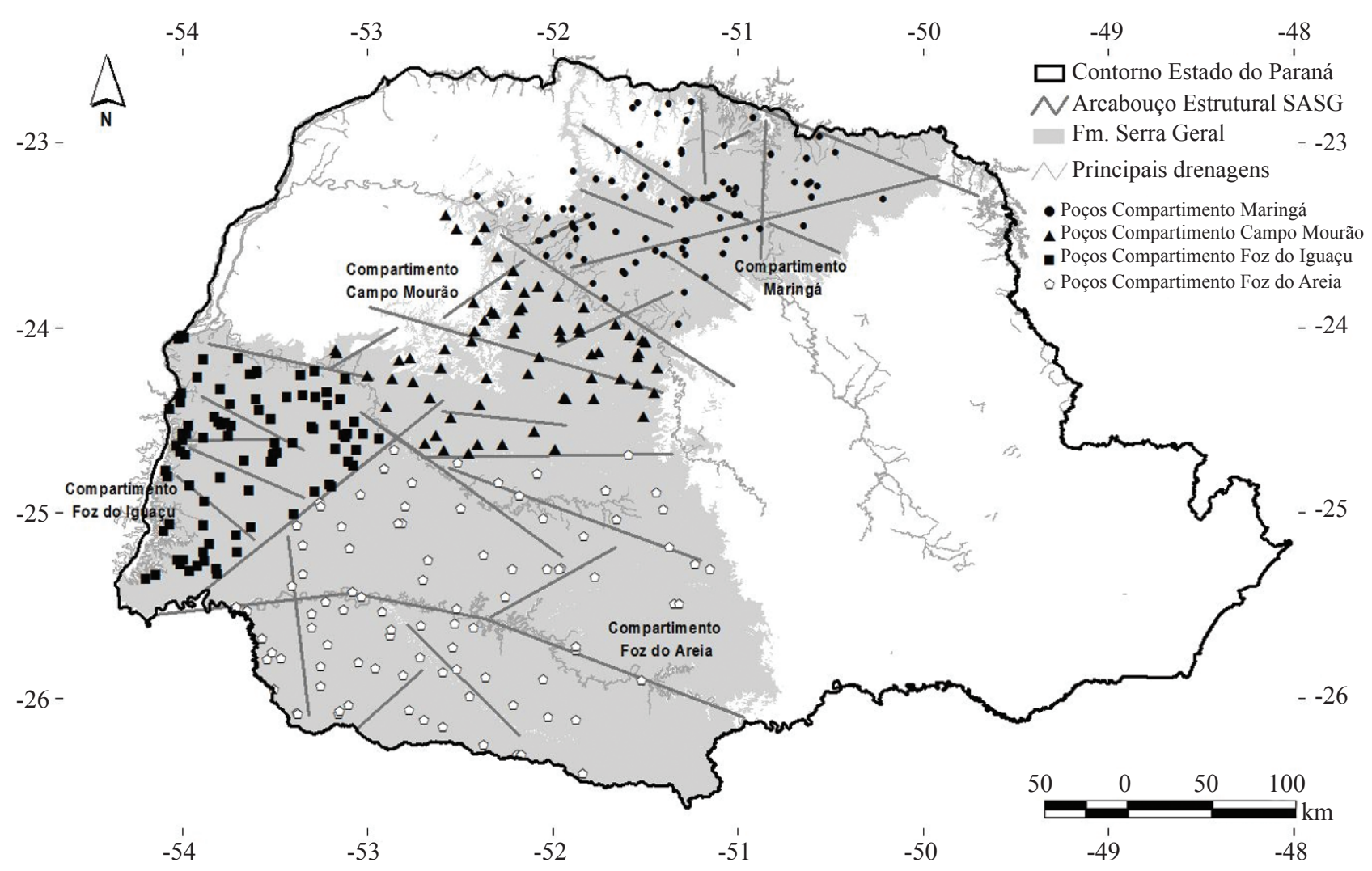

Figura 12 - Compartimentos Hidroestruturais definidos. 
Tabela 4 - Análise estatística da capacidade específica dos poços tubulares profundos separados por Compartimentos Hidroestruturais

\begin{tabular}{|c|c|c|c|c|}
\hline \multicolumn{5}{|c|}{ Análise dos compartimentos - capacidade específica dos poços tubulares } \\
\hline & Maringá & Campo Mourão & Foz do Iguaçu & Foz do Areia \\
\hline Quantidade de dados & 82 & 65 & 91 & 91 \\
\hline Valor mínimo $\left(\mathrm{m}^{3} / \mathrm{h} / \mathrm{m}\right)$ & 0,1 & 0,1 & 0,02 & 0,01 \\
\hline Valor máximo $\left(\mathrm{m}^{3} / \mathrm{h} / \mathrm{m}\right)$ & 44,35 & 23,66 & 314,62 & 34,82 \\
\hline \multicolumn{5}{|l|}{ Medidas de tendência central } \\
\hline & Maringá & Campo Mourão & Foz do Iguaçu & Foz do Areia \\
\hline Média geométrica $\left(\mathrm{m}^{3} / \mathrm{h} / \mathrm{m}\right)$ & 2,06 & 1,76 & 1,94 & 0,82 \\
\hline Mediana $\left(\mathrm{m}^{3} / \mathrm{h} / \mathrm{m}\right)$ & 2,38 & 2,08 & 2,08 & 0,9 \\
\hline Moda $\left(\mathrm{m}^{3} / \mathrm{h} / \mathrm{m}\right)$ & 0,12 & 0,48 & 0,21 & 0,09 \\
\hline \multicolumn{5}{|l|}{ Medidas de dispersão } \\
\hline & Maringá & Campo Mourão & Foz do Iguaçu & Foz do Areia \\
\hline Variância & 2,26 & 2,17 & 3,40 & 2,93 \\
\hline Desvio padrão geométrico & 1,50 & 1,47 & 1,84 & 1,71 \\
\hline $\mathrm{CV}(\%)$ & 73,07 & 83,69 & 94,80 & 208,22 \\
\hline \multicolumn{5}{|l|}{ Medidas de posicionamento } \\
\hline & Maringá & Campo Mourão & Foz do Iguaçu & Foz do Areia \\
\hline Primeiro quartil $\left(\mathrm{m}^{3} / \mathrm{h} / \mathrm{m}\right)$ & 0,85 & 0,9 & 0,72 & 0,29 \\
\hline Segundo quartil $\left(\mathrm{m}^{3} / \mathrm{h} / \mathrm{m}\right)$ & 2,38 & 2,08 & 2,08 & 0,9 \\
\hline Terceiro quartil $\left(\mathrm{m}^{3} / \mathrm{h} / \mathrm{m}\right)$ & 5,17 & 4,83 & 5,56 & 2,93 \\
\hline
\end{tabular}

CV: coeficiente de variação.

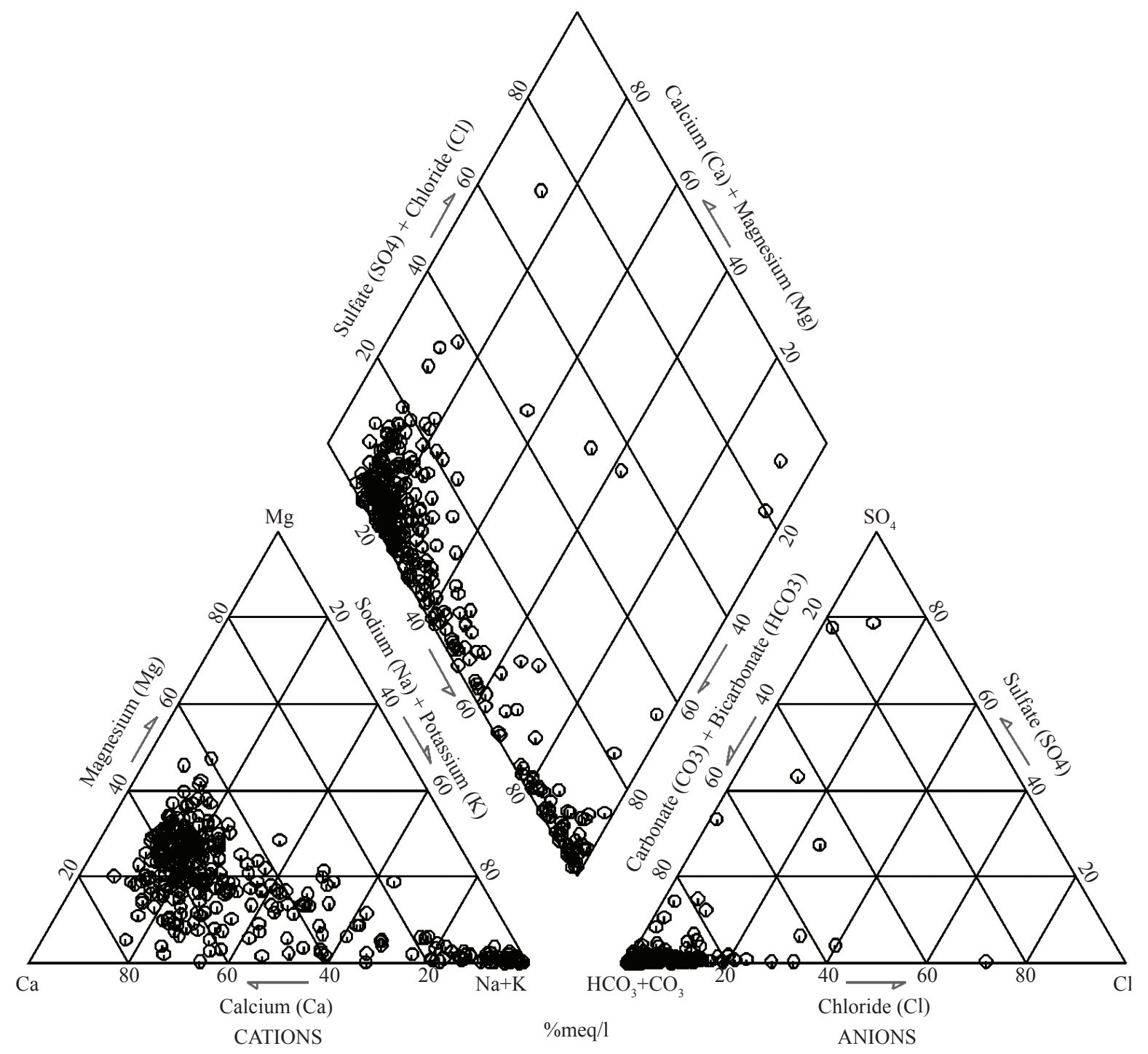

Figura 13 - Diagramas de Piper das amostras coletadas no Sistema Aquifero Serra Geral. 
Em menor número ocorrem os seguintes tipos hidroquímicos: bicarbonatada sulfatada sódica (duas amostras); bicarbonatada-carbonatada sódica (duas amostras); sulfatada sódica (uma amostra); bicarbonatada -magnésio cálcica (uma amostra); bicarbonatada nitrato sódica (uma amostra) e nitratada cálcica sódica (uma amostra).

O mapa com a localização dos tipos de água classificados é apresentado na Fig. 14.

\section{APTIDÃO DAS ÁGUAS DO SASG PARA CONSU-} MO HUMANO IN NATURA Dentre os poços analisados que captam o SASG, observaram-se ocorrências de teores acima dos máximos permitidos, quando comparado a valores orientadores (Brasil 2011) em 50 poços. Nestes casos, os íons analisados cujos teores restringem a utilização das águas in $n a-$ tura são apresentados na Tab. 5. Na Fig. 15, é apresentado um mapa com a localização dos poços cujos teores estão acima dos VMP.

APTIDÃO DAS ÁGUAS DO SASG PARA IRRIGAÇÃO De maneira geral, as águas do SASG podem ser utilizadas para irrigação, quando analisadas pelo método SAR (sodium adsorption ratio). Segundo essa metodologia, observa-se que das 337 amostras analisadas do SASG, 3 merecem atenção por possuírem qualidades impróprias para irrigação.

Na Tab. 6, observa-se a classificação das 337 amostras do Sistema Aquífero Serra Geral.

Analisando o risco de salinidade das águas, observou-se que três amostras possuem risco alto à salinidade (Tab. 7).

Com relação ao risco de sódio verifica-se que 12 amostras apresentaram risco forte a muito forte (Tab. 8).

A localização de todos os poços com restrição de uso in natura para irrigação é apresentada em mapa na Fig. 16.

Tabela 5 - Íons com concentrações acima dos valores máximos permitidos

\begin{tabular}{lc}
\hline Parâmetro & Número de poços com teores acima do VMP \\
\hline Sódio & 2 \\
\hline Sulfato & 2 \\
\hline Fluoreto & 6 \\
\hline Ferro total & 2 \\
\hline STD & 1 \\
\hline pH & 36 \\
\hline Nitrato & 1
\end{tabular}

VMP: valores máximos permitidos; STD: sólidos totais dissolvidos.

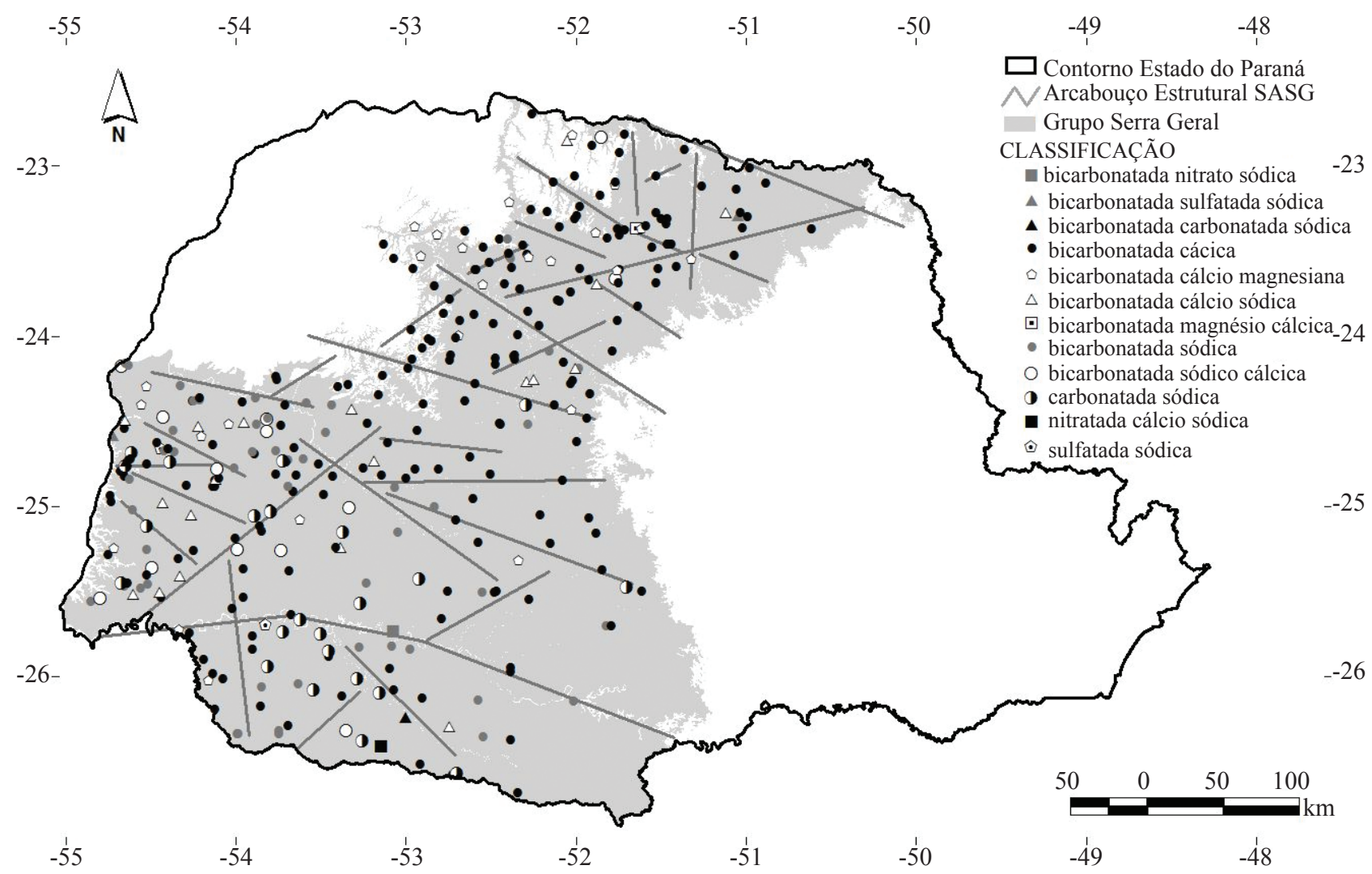

Figura 14 - Mapa com a distribuição dos tipos de água classificados para o Sistema Aquífero Serra Geral. 


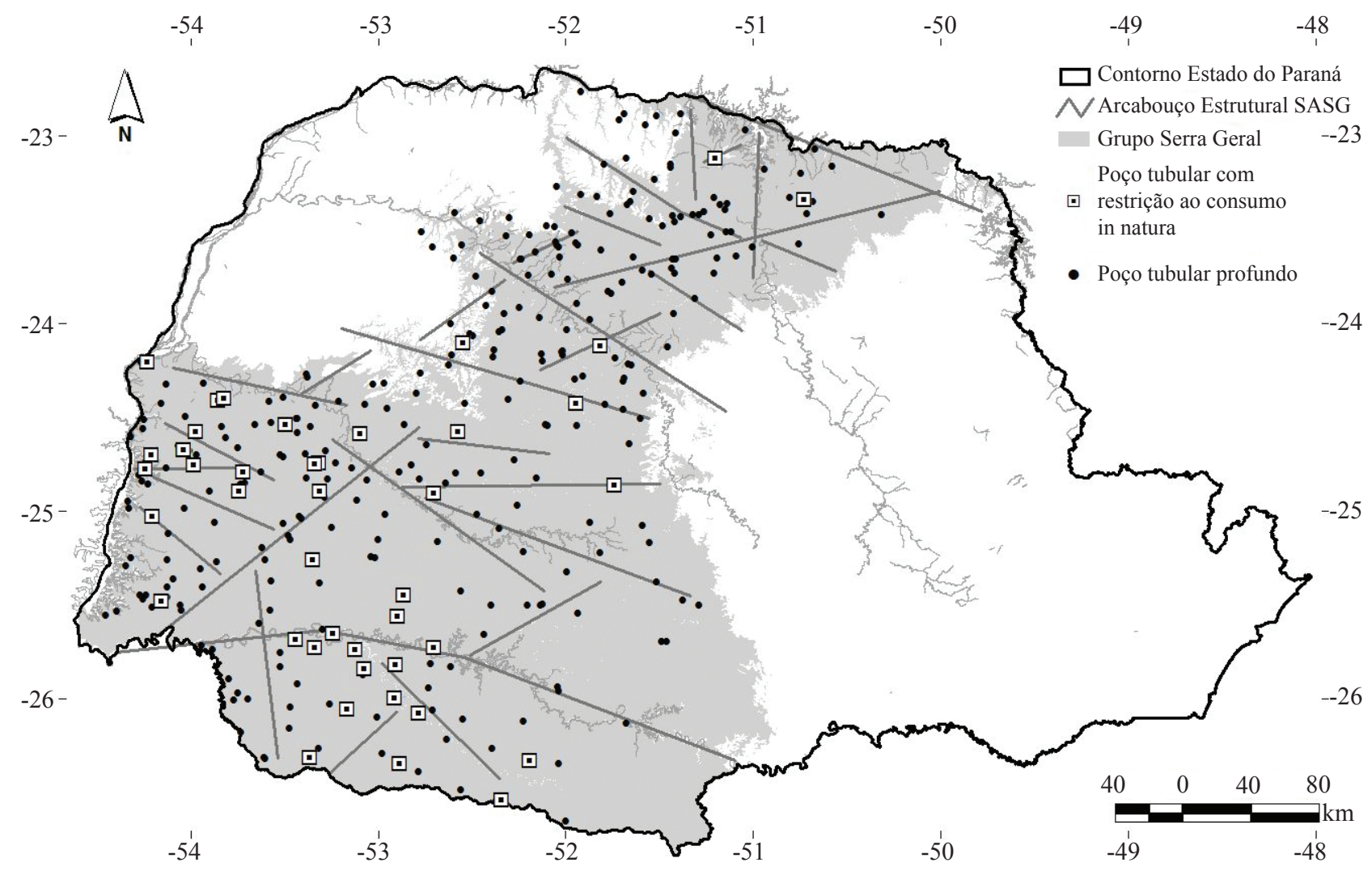

Figura 15 - Mapa com a localização dos poços cujos teores estão acima dos valores máximos permitidos.

Tabela 6 - Classificação das águas para irrigação no Sistema Aquífero Serra Geral

\begin{tabular}{lccccc}
\hline Classificação & $\mathrm{N}^{\circ}$ casos & \% ocorrência & Classificação & $\mathrm{N}^{\circ}$ casos & \% ocorrência \\
\hline C0-S1 & 51 & 15,1 & C3-S1 & 0 & 0 \\
\hline C0-S2 & 0 & 0 & C3-S2 & 0 & 0 \\
\hline C0-S3 & 0 & 0 & C3-S3 & 1 & 0,3 \\
\hline C0-S4 & 0 & 0 & C3-S4 & 2 & 0,6 \\
\hline C1-S1 & 217 & 64,4 & C4-S1 & 0 & 0 \\
\hline C1-S2 & 11 & 3,3 & C4-S2 & 0 & 0 \\
\hline C1-S3 & 1 & 0,3 & C4-S3 & 0 & 0 \\
\hline C1-S4 & 0 & 0 & C4-S4 & 0 & 0 \\
\hline C2-S1 & 41 & 12,2 & C5-S1 & 0 & 0 \\
\hline C2-S2 & 5 & 1,5 & C5-S2 & 0 & 0 \\
\hline C2-S3 & 7 & 2,1 & C5-S3 & 0 & 0 \\
\hline C2-S4 & 1 & 0,3 & C5-S4 & 0 & 0 \\
\hline
\end{tabular}

Tabela 7 - Classificação em relação à salinidade

\begin{tabular}{lccc}
\hline Classificação & Risco & $\mathrm{N}^{\circ}$ casos & \% ocorrência \\
\hline $\mathrm{C} 0$ & Nulo & 51 & 15,1 \\
\hline $\mathrm{C} 1$ & Baixo & 229 & 67,9 \\
\hline $\mathrm{C} 2$ & Médio & 54 & 16,0 \\
\hline $\mathrm{C} 3$ & Alto & 3 & 0,9 \\
\hline $\mathrm{C} 4$ & Muito alto & 0 & 0 \\
$\mathrm{C} 5$ & $\begin{array}{c}\text { Excepcionalmente } \\
\text { alto }\end{array}$ & 0 & 0 \\
\hline
\end{tabular}

Tabela 8-Classificação em relação ao risco de sódio

\begin{tabular}{lccc}
\hline Classificação & Risco & $\mathrm{N}^{\circ}$ casos & \% ocorrência \\
\hline S1 & Baixo & 309 & 91,7 \\
\hline S2 & Médio & 16 & 4,8 \\
\hline S3 & Forte & 9 & 2,7 \\
\hline S4 & Muito forte & 3 & 0,9 \\
\hline
\end{tabular}

CONCLUSÕES Considerando a qualidade das águas e a potencialidade de produção do SASG no estado do Paraná, este é, sem dúvida, um aquífero estratégico sob o ponto de vista da demanda de consumo humano.

A análise de 337 poços tubulares distribuídos no estado do Paraná permitiu identificar as principais direções de fluxo do aquífero. O sentido regional é de leste para oeste, principalmente influenciado pelo mergulho da Fm. Serra Geral.

A distribuição espacial dos poços com vazões e capacidades específicas acima do terceiro quartil permitiu caracterizar duas Províncias Hidroestruturais (Jacutinga Noroeste e Jacutinga Sudeste). A Província Hidroestrutural Jacutinga Noroeste é a mais produtiva. 


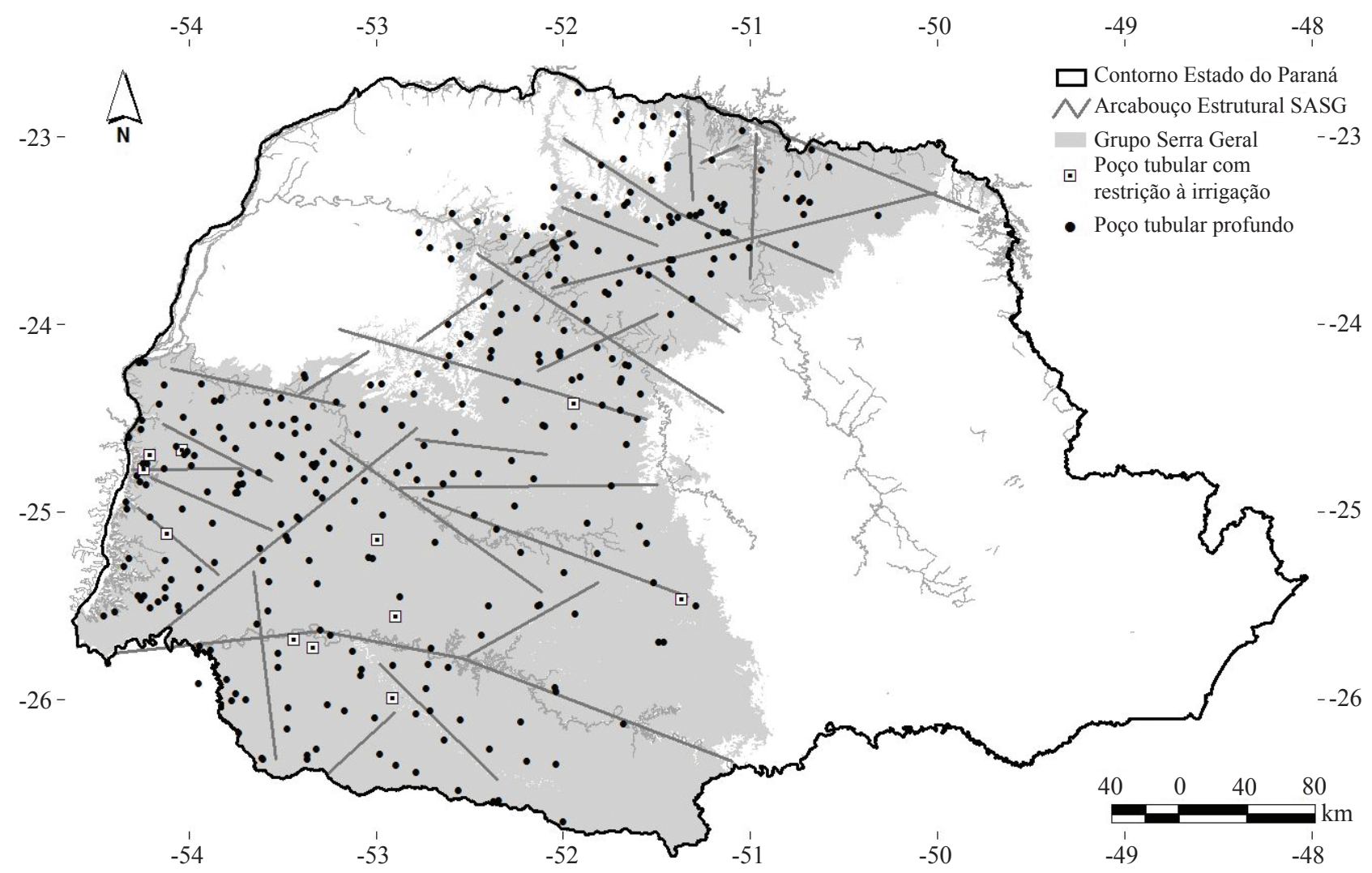

Figura 16 - Mapa com a localização dos poços com águas impróprias para irrigação, in natura.

Detalhando a análise destas províncias, foi possível identificar quatro Compartimentos Hidroestruturais (Maringá, Campo Mourão, Foz do Iguaçu e Foz do Areia), com destaque para os compartimentos hidroestruturais Maringá e Foz do Iguaçu, onde os poços possuem bom índice de produção (mediana de capacidade específica de 2,38 e 2,08 $\mathrm{m}^{3} \mathrm{~h}^{-1} \mathrm{~m}^{-1}$, respectivamente).

Ocompartimento Campo Mourão possui a mesma mediana de capacidade específica que o Compartimento Foz do Iguaçu, entretanto considerando as vazões de exploração, Foz do Iguaçu apresenta poços tubulares com vazões superiores. O compartimento Foz do Areia representa o local com maior risco exploratório, visto que os poços possuem menor produtividade (mediana da capacidade específica de $\left.0,9 \mathrm{~m}^{3} \mathrm{~h}^{-1} \mathrm{~m}^{-1}\right)$.

O SASG possui excelente qualidade química para consumo in natura. Grande parte das restrições químicas (36 casos em 50) estão associados ao pH, parâmetro facilmente corrigido com processos químicos simplificados, necessários à distribuição desta água para abastecimento.

Ocorrências localizadas e associadas de nitrato, fosfato e potássio podem estar relacionadas aos efluentes antrópicos em áreas urbanas e/ou à aplicação de corretivos agrícolas, uma vez que ocorrem poços situados nestes tipos de uso e ocupação do terreno.

\section{AGRADECIMENTOS Os alunos Gustavo} Barbosa Athayde e Camila de Vasconcelos Müller Athayde agradecem à Coordenação de Aperfeiçoamento de Pessoal de Nível Superior (CAPES) pela concessão da bolsa de estudos, Programa PROF - CAPES; Pós-Graduação em Geologia/Universidade Federal do Paraná (UFPR).

\section{Referências}

Athayde G., Müller C., Rosa Filho E., Hindi E. 2007. Estudo sobre os tipos das águas do Aquífero Serra Geral, no município de Marechal Cândido Rondon- Pr. Águas Subterrâneas, 21(1):111-122.

Athayde G.B. 2010. Diretrizes da SANEPAR na prospecção e monitoramento de aquíferos no Estado do Paraná. In: XVI Congresso Brasileiro de Águas Subterrâneas e XVII Encontro nacional de perfuradores de poços, 2010, São Luis.

BRASIL. 2011. Ministério da Saúde. Portaria no 2914 de 12 de dezembro de 2011. Dispõe sobre os procedimentos de controle e de vigilância da qualidade da água para consumo humano e seu padrão de potabilidade. Diário Oficial da União, Brasília, p. 43-49, 04 jan. 2012, Seção 1. 
Fraga, G. C. 1986. Introdução ao zoneamento do Sistema Aquífero Serra Geral no Estado do Paraná. 1986. 132 p. Dissertação de (Mestrado,) - Instituto de Geociências, Universidade de São Paulo, - USP, São Paulo, 132 p1986.

Licht O.A.B. 2001. Análise multielementar na gestão ambiental - Identificação e caracterização de Províncias Geoquímicas naturais, alterações antrópica da paisagem, áreas favoráveis à prospecção mineral e regiões de risco para a saúde no Estado do Paraná, Brasil. Tese de Doutorado em Geologia, Setor de Ciências da terra, Universidade Federal do Paraná, Curitiba, V1-V2, $209 \mathrm{f}$.

Melfi A.J., Piccirillo E.M., Nardy A.J.R. 1988. Geological and magmatic aspects of the Parana Basin: an introduction. In: Piccirillo E.M. \& Melfi A.J. (Eds.). The Mesozoic Flood Volcanism of the Parana Basin: petrogenetic and geophysical aspects. São Paulo, USP, p. 1-14.

Mellanger M., Chork S.C.Y., Dijkstra S., Esbensen K.H., Kürzl H., Lindqvist L., Saheurs J.P., Schermann O., Siewers U., Westerberg K. 1984. The multivariate chemical space and the integration of the chemical, geographical and geophysical spaces. Journal of Geochemical Exploration, 21(1-3):143-148.

Milani E.J. 2004. Geologia do continente sul americano: comentários sobre a origem e evolução tectônica da Bacia do Paraná. São Paulo, Beca, p. 265-279.

MINEROPAR. 2006. Minerais do Paraná S.A. Mapa geológico do Estado do Paraná. Curitiba, Mineropar, escala 1:650.000

O’Leary. D.W., Friedman J.D., Pohn H.A. 1976. Lineament, linear lineation some proposed new standards for old terms. Geological Society America Bulletin, 87(10):1463-1469.
Piper A.M. 1944. A graphic procedure in the geochemical interpretation of water-analyses. Transactions of the American Geophysical Union, 25:914-928.

Portela Filho C.V., Ferreira F.J.F., Rosa Filho E.F., Buchmann Filho A.C., Rostirolla S.P. 2002. Estudo preliminar da conexão entre os aquíferos Serra Geral e Guarani com base em dados aeromagnetométricos e hidroquímicos. In: XII Congresso Brasileiro de Águas Subterrâneas, 16 p, 2002, Florianópolis.

Rosa Filho E.F., Hindi E.C. 2006. Diagnóstico das águas subterrâneas no Estado do Paraná: quantidade e qualidade. Relatório técnico, 103p.

Soares A.P., Soares P.C., Bettu D.F., Holz M. 2007. Variabilidade espacial no Sistema Aquífero Guarani: controles estruturais e estratigráficos. Águas Subterrâneas, 21(1):51-64.

SRTM USGS; EROS Data Center; Data Services Branch. Seamless Data Distribution System. Disponível em: http://seamless.usgs.gov/. Acessado em: 12/11/2005.

SUDERHSA. 2007. Instituto das Águas do Paraná. Bacias hidrográficas do Paraná. Disponível em: http://www. aguasparana.pr.gov.br/modules /conteudo/conteudo. php. Acessado em: 10/07/2010.

Thiede D.S., Vasconcelos P.M. 2010. Parana flood basalts: Rapid extrusion hypothesis confirmed by new 40Ar/39Ar results. Geology, 38(8):747-750.

U.S. Salinity Staff. 1954. Diagnosis and improvement of saline and alkali soils. U. S. Department of agriculture. In: Agriculture Handbook, Washington, DC, n. 60, 160 p.

Manuscrito ID 22372

Recebido em: 27/07/2011

Aprovado em: 25/09/2012 